\title{
Experimental investigation into finite similitude for metal forming processes
}

DOI:

10.1016/j.jmatprotec.2018.07.028

\section{Document Version}

Accepted author manuscript

Link to publication record in Manchester Research Explorer

\section{Citation for published version (APA):}

Al-tamimi, A., Darvizeh, R., \& Davey, K. (2018). Experimental investigation into finite similitude for metal forming processes. Journal of Materials Processing Technology, 262, 622-637.

https://doi.org/10.1016/j.jmatprotec.2018.07.028

\section{Published in:}

Journal of Materials Processing Technology

\section{Citing this paper}

Please note that where the full-text provided on Manchester Research Explorer is the Author Accepted Manuscript or Proof version this may differ from the final Published version. If citing, it is advised that you check and use the publisher's definitive version.

\section{General rights}

Copyright and moral rights for the publications made accessible in the Research Explorer are retained by the authors and/or other copyright owners and it is a condition of accessing publications that users recognise and abide by the legal requirements associated with these rights.

\section{Takedown policy}

If you believe that this document breaches copyright please refer to the University of Manchester's Takedown Procedures [http://man.ac.uk/04Y6Bo] or contact uml.scholarlycommunications@manchester.ac.uk providing relevant details, so we can investigate your claim.

\section{OPEN ACCESS}




\title{
Experimental investigation into finite similitude for metal forming processes
}

\author{
Anees Al-Tamimi ${ }^{a}$, Rooholamin Darvizeh ${ }^{a}$, Keith Davey ${ }^{a b} *$ \\ ${ }^{a}$ School of Mechanical, Aerospace and Civil Engineering, The University of Manchester. \\ ${ }^{\mathrm{b}}$ Advanced Forming Research Centre, University of Strathclyde.
}

\begin{abstract}
Applied in this paper is a new technique for scaling metal forming processes, founded on the idea that scaling can be achieved by scaling space itself. With this approach, the physics in two spaces is described using transport equations and are deemed to possess finite similitude if found to be proportional. Finite similitude can be shown to always exist in continuum mechanics for isotropic scaling and it is demonstrated here how the concept can be used to design experiments. Validation of the approach is achieved by means of scaled experimental, numerical and analytical solutions of scaled upsetting tests for cylindrical and ring samples. Three trial materials are tested and distinguished by the degree of strain softening, strain hardening and near perfect-plastic behaviour. Finite similitude results confirm that any discrepancies between the maximum loads are substantially reduced when the new scaling theory is applied. Best results are obtained when the same material is adopted for both full and small-scale experimentation.
\end{abstract}

Keywords: Scaling; Metal Forming; Finite Similitude

*Corresponding Author

Email keith.davey@manchester.ac.uk 


\section{Introduction}

Metal forming processes continue to be an area of active research as industry strives for improvements in processing performance and better control of product quality. Modern industrial practice for metal forming still depends heavily on trial-and-error testing over large ranges of strain, strain rates and temperatures, which the associated high-capacity machine requirements and elevated production costs. Finite element analysis is also employed but is not without its limitations, as it depends heavily on constitutive laws, which in turn require experimental data. It is often not sufficiently accurate due to its numerous simplifications on microstructure, boundary conditions and invariably requires post-process analysis, i.e. adjustment of boundary conditions and constitutive models. Multiscale simulations if employed can also be computationally expensive and invariably are unable to capture the broad ranges of physical behaviours over the wide range of length scales involved.

A complementary approach is to use the concept of similarity, with the testing of scaled models to better understand the full-scale behaviour. The approach is not new and many attempts have been made to predict loads and behaviour of real metal-forming processes using scaled models with different scaling factors and materials as described by Hertel (1966). The capability of the similitude theory to predict the metal flow of the large-scale, was earlier studied by Heuer (1962)), and then subsequently by Chang and Brittain (1968). Each employed material models such as wax, plasticine, and clay to obtain information about metal flow and loading requirements. Altan et al. (1968) investigated the forming loads of forward and backward extrusion processes with various steels using scaled models made from plasticine. The drawback with these approaches is that model materials do not permit microstructural evaluation, which can be a process requirement. More recently Cho et al. (2005) conducted an experimental study using identical materials for both full and small trials. Interest in scaled models and model materials persists however with Mazzariol et al. (2016) performing an analytical and experimental study with scaled models using a range of different scaling factors and materials. They considered alloys of Magnesium, Aluminium, Titanium, Steel, Cartridge Brass and Tungsten in an attempt to predict behaviours at the fullscale. They concluded that material properties of the scaled model on applying their scaling law provided different behaviours to the full-scale process. In particular, they noted higher forces were required when brass and aluminum are used yet tungsten and titanium produced the opposite. It is recognized however that scaling laws of this type have severe limitations and typically require modification (i.e. incorporation of correction factors) in order to relate the difference in material flow stress between the full and scale models as recommended by Westine and Mullin (1987) and Oshiro and Alves (2009). Alternative approaches for the establishment of similarity conditions in the metal forming process use dimensional analysis (Buckingham-Pi theorem), but its application to metal forming is somewhat limited and has little impact on modern practices. Pawelski (1992) for example provides one of the few useful examples of dimensional analysis applied to a metal forming process. His analysis is founded on the Buckingham-Pi theorem and was used to describe the influence of lubricants in cold rolling. Similarly, Navarrete et al. (2001) illustrated how dimensional analysis could be used to calculate compressive loads for a closed-die forging process. The types of analysis performed with dimensional analysis have to-date only provided information on relatively simple geometries in metal forming processes. As confirmed by Pawelski (1964), complete and exact similarity solutions seldom exist; which is the same conclusion reached by Sedov (1993), for thermomechanical deformation processes. It is virtually impossible to satisfy all the constraints in metal forming and at the same time scale the process. 
The research presented in this paper is founded on a new concept called finite similitude to overcome these limitations. The focus of finite similitude is on space and particularly on transfers of mass, momentum, energy, entropy etc into and out of an identified region. Finite similitude is defined on finding transfers which are proportional when contrasting two regions of space where one contains a process of interest and the other a scaled replica. The focus on space is captured with the control-volume methodology and the use of transport equations in their integral form. It has recently been demonstrated that finite similitude always exists for continuum mechanics, no matter how involved the process. Transport equations can be applied over a vast range of length scales making the concept particularly important to processes such as metal forming where microstructural influences play a critical role. With this approach, transport equations are considered although initially absent of any constitutive information; this is a critical step because the constitutive laws are the principal reason why similarity is not achievable in metal forming. The conditions for finite similitude are not dependent on constitutive information as transfers to and from a region of space do not require such knowledge. Once the relationships for finite similitude are known, then constitutive information can be investigated and materials selected in an attempt to achieve inexact similarity. One important aspect of the new similitude approach is that it allows similar solutions to be projected between the two regions of space (i.e. the trial and physical space) and thus provides a means to quantify any deviation from similarity. This feature provides a route for the design of a physical experiment and the subsequent projection of this experiment into the physical space to ascertain its validity.

This paper focuses on an experimental investigation into the application of the concept of finite similitude. The experimental trials pertain to relatively simple upsetting processes, which are considered and complemented by finite element and analytical analysis. The paper examines the idea of mapping similarity solutions between the physical and trial spaces to illustrate how information from a scaled experiment can be used to approximately gauge the behaviour of a full-scale process. The founding finite similitude theory is introduced in Section 2 along with scaling relationships for isotropic scaling. The experimental apparatus and materials used in the research, for the investigation of the cold upsetting tests, are presented in Section 3 for both full and trial space models. Section 3.1 contains a description of the finite element model and selected boundary conditions applied for numerical simulation. Examined in Section 3.4 are the results of the experimentation and the finite element analysis for the scaled upsetting process. Analytical results are included in Section 4 for cylinders and rings in order to illustrate further the applicability of the new scaling theory to different forms of analysis. Finally, conclusions are supplied to review the relative merits of the finite similitude approach.

\section{Finite Similitude Theory}

The theory considered in this section is concerned with the laws governing processes contained in a finite region of space. The idea is to mathematically scale space and to describe the effects that this has on the processes under consideration. The scaling of space in this way provides excellent flexibility since extraordinarily complex processes can be involved yet can be scaled. The focus on space means that a mathematical description is required that readily captures transport phenomenon in and out of a region of space. Integral transport forms of the conservation equations applied to a control volume $\Omega_{p s}$ provide an appropriate platform for the underpinning theory. As illustrated in Darvizeh and Davey 
(2012), a generic transport equation for the physical space (i.e. the space of the full-scale model) is

$$
\frac{D^{*}}{D^{*} t} \int_{\Omega_{p s}} \rho_{p s} \psi \psi_{p s} d V_{p s}+\int_{\Gamma_{p s}} \rho_{p s} \psi \psi_{p s}\left(\underline{v}_{p s}-\underline{v}_{p s}^{*}\right) \cdot \underline{n}_{p s} d \Gamma_{p s}=-\int_{\Gamma_{p s}} \underline{J}_{p s}^{\psi} \cdot \underline{n}_{p s} d \Gamma_{p s}+\int_{\Omega_{p s}} \rho_{p s}{ }_{p s}^{\psi} d V_{p s}
$$

where $\rho$ is the density, $\psi$ is a physical field, $\underline{v}$ is the material velocity field, $\underline{v}^{*}$ is the control volume velocity, $\underline{J}$ is the flux, $b$ is the body force, $\underline{n}$ is the unit normal to the boundary $\Gamma$ of the control volume $\Omega$.

Ten transport equations are involved in describing metal forming processes under a continuum-mechanics framework and pertinent to similitude. These are described by Equation (1) for different settings of the field $\psi$ for the transport of: volume $\left(\psi=\rho^{-1}\right)$, mass $(\psi=1)$, momentum $(\psi=\underline{v})$, movement $(\psi=\underline{u})$, energy $(\psi=u+0.5 \underline{v} \cdot \underline{v})$ and entropy ( $\psi=s$ ), where $\underline{u}$ is displacement, $u$ is specific internal energy, and $s$ is specific entropy. There are an identical set of transport equations governing the physics in the trial space

$$
\frac{D^{*}}{D^{*} \tau} \int_{\Omega_{t s}} \rho_{t s} \psi_{t s} d V_{t s}+\int_{\Gamma_{t s}} \rho_{t s} \psi_{t s}\left(\underline{v}_{t s}-\underline{v}_{t s}^{*}\right) \cdot \underline{n}_{t s} d \Gamma_{t s}=-\int_{\Gamma_{t s}} \underline{J}_{t s}^{\psi} \cdot \underline{n}_{t s} d \Gamma_{t s}+\int_{\Omega_{t s}} \rho_{t s} b_{t s}^{\psi} d V_{t s}
$$

where in this case time is assumed to run at a different rate expressed by the use of the symbol $\tau$.

Equation (1) and (2) are presently unrelated but can be related through the assumed differential maps for time $d t=h(\tau) d \tau$ (or $d \tau=g(t) d t$ ) and space $\boldsymbol{d} \boldsymbol{x}=F_{s} \cdot \boldsymbol{d s}$. As Itskov (2007) noted, this latter map provides Nanson's geometric identities of the form $d V_{p s}=\left|F_{s}\right| d V_{t s}$ and $n_{p s} d \Gamma_{p s}=\left|F_{s}\right| n_{t s} d \Gamma_{t s} \cdot F_{s}^{-1}$. Substituting these identities into Equation (1) gives

$\frac{1}{h} \frac{D^{*}}{D^{*} \tau} \int_{\Omega_{s s}^{*}} \rho_{p s} \psi_{p s}\left|F_{s}\right| d V_{t s}+\int_{\Gamma_{s s}^{*}} \rho_{p s} \psi_{p s}\left|F_{s}\right| F_{s}^{-1} \cdot\left(\underline{v}_{p s}-\underline{v}_{p s}^{*}\right) \cdot \underline{n}_{t s} d \Gamma_{t s}=-\int_{\Gamma_{s s}^{*}}\left|F_{s}\right| F_{s}^{-1} \cdot \underline{J}_{p s}^{\psi} \cdot \underline{n}_{t s} d \Gamma_{t s}+\int_{\Omega_{s s}^{*}} \rho_{p s} b_{p s}^{\psi}\left|F_{s}\right| d V_{t s}$

Multiplication of Equation (3) by a scalar $\alpha^{\psi}$ (and $h$ ) and on matching the integrands in Equation (2) reveals the following scaling identities:

$$
\begin{aligned}
& \rho_{t s}^{\psi} b_{t s}=\alpha^{\psi} h \rho_{p s} b_{p s}^{\psi}\left|F_{s}\right| \\
& \underline{J}_{t s}^{\psi}=\alpha^{\psi} h\left|F_{s}\right| F_{s}^{-1} \cdot \underline{J}_{p s}^{\psi} \\
& \underline{v}_{t s}-\underline{v}_{t s}^{*}=h F_{s}^{-1} \cdot\left(\underline{v}_{p s}-\underline{v}_{p s}^{*}\right) \\
& \rho_{t s}^{\psi} b_{t s}=\alpha^{\psi} h \rho_{p s} b_{p s}^{\psi}\left|F_{s}\right|
\end{aligned}
$$

which yield finite similitude if satisfied for the transport equations for volume, mass, momentum, movement, energy and entropy.

\subsection{Isotropic finite similitude}

The physical length parameters for isotropic scaling have the same ratio in all directions. In this case therefore, the deformation gradient tensor $F_{s}$ takes its simplest form and is equal to 
$\beta I$, where $\beta$ is a scaling factor and $I$ is the identity tensor. Substituting the relationship $\left|F_{s}\right|=\beta^{3}$ into the equations (4a-d) results in the following isotropic scaling equations: $\rho_{s s} \psi_{t s}=\alpha^{\psi \prime} \beta^{3} \rho_{p s} \psi_{p s}, \quad \underline{v}_{t s}-\underline{v}_{t s}^{*}=h \beta^{-1}\left(\underline{v}_{p s}-\underline{v}_{p s}^{*}\right), \quad \underline{J}_{t s}^{\psi}=\alpha^{\psi} h \beta^{2} \underline{J}_{p s}^{\psi} \quad$ and $\quad \rho_{t s} b_{t s}^{\psi \prime}=\alpha^{\psi} h \beta^{3} \rho_{p s} b_{p s}^{\psi \prime}$. As demonstrated by Davey et al. (2017), it is possible to match equations (2) and (3) for all transport equations but of particular interest here are the equations for volume, mass, momentum, movement and energy. The matching process provides relationships for the physical variables $\rho_{t s}, \psi_{p s}, \underline{v}_{p s}^{*}, \underline{v}_{t s}, \underline{J}_{t s}^{\psi}$ and $b_{t s}^{\psi}$ along with scaling parameters $\alpha^{\psi}, \beta$ and $h$. Consider then the conservation of volume (with $\psi=\rho^{-1}$ ), which reveals $1=\alpha^{1} \beta^{3}$ and $\underline{v}_{t s}^{*}=h \beta^{-1} \underline{v}_{p s}^{*}$. These two identities have important implications; first the scaling parameter $\alpha^{1}$ is arbitrary and therefore suggests that $\beta$ is arbitrary; second, $\underline{v}_{t s}-\underline{v}_{t s}^{*}=h \beta^{-1}\left(\underline{v}_{p s}-\underline{v}_{p s}^{*}\right)$ splits into two relationships $\underline{v}_{-t s}^{*}=h \beta^{-1} \underline{v}_{p s}^{*}$ and $\underline{v}_{t s}=h \beta^{-1} \underline{v}_{p s}$. The arbitrariness of $\beta$ is a consequence of the theory but in practice, practical limitations impose constraints. Consider further conservation of mass (with $\psi=1$ ), which reveals the density relationship $\rho_{t s}=\alpha^{\rho} \beta^{3} \rho_{p s}$ and again the expression $\underline{v}_{t s}-\underline{v}_{t s}^{*}=h \beta^{-1}\left(\underline{v}_{p s}-\underline{v}_{p s}^{*}\right)$ (satisfied by $\underline{v}_{t s}^{*}=h \beta^{-1} \underline{v}_{p s}^{*}$ and $\underline{v}_{t s}=h \beta^{-1} \underline{v}_{p s}$ ); here $\alpha^{\rho}$ is termed the density scaling factor. Things are a little more involved with momentum scaling where the field variable $\psi$ is set to material velocity $\underline{v}$ and momentum related flux $\underline{J}=\underline{\underline{\sigma}}$. Equations (4a), (4b) and (4d) provide $\rho_{t s} \underline{v}_{t s}=\alpha^{\underline{v}} \beta^{3} \rho_{p s} \underline{v}_{p s}, \quad \rho_{t s} \underline{b}_{t s}=\alpha^{\underline{v}} h \beta^{3} \rho_{p s} \underline{b}_{p s} \quad$ and $\underline{\underline{\sigma}}_{t s}=\alpha^{\underline{v}} h \beta^{2} \underline{\underline{\sigma}}_{p s}$, where this latter relationship can be used to relate constitutive behaviour. For example, with $\bar{\sigma}$ and $\underline{\underline{\sigma^{\prime}}}$ defined as effective and deviatoric stresses the von Mises identities ${\underline{\underline{\sigma^{\prime}}}}_{p s}^{\prime}:{\underline{\underline{\sigma_{p s}^{\prime}}}}^{\prime}=\frac{2}{3} \bar{\sigma}_{p s}^{2}$ and ${\underline{\underline{\sigma^{\prime}}}}_{t s}: \underline{\underline{\sigma}}_{t s}^{\prime}=\frac{2}{3} \bar{\sigma}_{t s}^{2}$ provide a relationship between effective stresses in both spaces, i.e. $\bar{\sigma}_{t s}=\alpha^{v} h \beta^{2} \bar{\sigma}_{p s}$. Such a relationship can be used to determine the temporal scaling factor $h$. Note first however that $\rho_{t s} \underline{v}_{t s}=\alpha^{\underline{v}} \beta^{3} \rho_{p s} \underline{v}_{p s}$ and $\underline{v}_{t s}=h \beta^{-1} \underline{v}_{p s}$ must be equal and given that $\rho_{t s}=\alpha^{\rho} \beta^{3} \rho_{p s}$ it immediately follows that $\alpha^{\rho} \underline{v}_{t s}=\alpha^{\underline{\underline{v}}} \underline{\underline{v}}_{p s}$ or $\alpha^{\underline{\underline{v}}}=\alpha^{\rho} h \beta^{-1}$, confirming that momentum scaling is not independent of mass scaling. Armed with this knowledge and on setting effective stress to initial yield (i.e. setting $\bar{\sigma}_{t s}=Y_{t s}$ and $\bar{\sigma}_{p s}=Y_{p s}$ ) the time scaling factor $h$ can be determined, i.e.

$h=\sqrt{\frac{1}{\alpha^{\rho} \beta} \frac{Y_{t s}}{Y_{p s}}}$

where $Y$ is the initial yield stress.

It is important to note that time scaling is a feature here, which might be expected to be absent in the analysis of quasi-static processes. Approaches such as dimensional analysis would typically not include time since quasi-static processes do not involve time by definition. The new approach recognises that there is simply no such thing as a quasi-static process (being an idealisation) and any experiment will involve time. The appearance of time scaling in all the experiments presented in the paper highlight this particular aspect.

Next is movement, which is not common to transport equations and was recently introduced by Davey et al. (2017) and is obtained on setting the field variable $\psi$ to material displacement $\underline{u}$ and moment related flux $\underline{J}=\underline{0}$ and movement source term $b_{t s}=\underline{v}$. In this 
case the similarity rules provide $\rho_{t s} \underline{u}_{t s}=\alpha^{\underline{u}} \beta^{3} \rho_{p s} \underline{u}_{p s}$ (or $\alpha^{\rho} \underline{u}_{t s}=\alpha^{\underline{u}} \underline{u}_{p s}$ ) and $\rho_{t s} \underline{v}_{t s}=\alpha^{\underline{u}} h \beta^{3} \rho_{p s} \underline{v}_{p s}$ (or $\alpha^{\rho} \underline{v}_{t s}=\alpha^{\underline{u}} h \underline{v}_{p s}$ ) but in view of the identity $\alpha^{\rho} \underline{v}_{t s}=\alpha^{\underline{v}} \underline{v}_{p s}$ it follows that movement scaling is not independent and $\alpha^{\underline{\underline{v}}}=\alpha^{\underline{\underline{u}}} h$.

Finally, consider now the transport equation for energy (neglecting heat transfer) where the physical field $\psi=e$, work related flux $\underline{J}=\underline{v} \cdot \underline{\underline{\sigma}}$ and body force related work rate $b=\underline{v} \cdot \underline{b}$. Evaluation of the similarity equations provides consistent relationships along with the identity $\rho_{t s} e_{t s}=\alpha^{e} \beta^{3} \rho_{p s} e_{p s}$. Substitution of the identity $\rho_{t s}=\alpha^{\rho} \beta^{3} \rho_{p s}$ and on splitting the total specific energy $e$ into specific internal energy $u$ and specific kinetic energy $\frac{1}{2} v^{2}$ gives $\alpha^{\rho}\left(u_{t s}+\frac{1}{2} v_{t s}^{2}\right)=\alpha^{e}\left(u_{p s}+\frac{1}{2} v_{p s}^{2}\right)$. It can immediately be deduced that $\alpha^{\rho} u_{t s}=\alpha^{e} u_{p s}$ and $\alpha^{\rho} \underline{v}_{t s} \cdot \underline{v}_{t s}=\alpha^{e} \underline{v}_{p s} \cdot \underline{v}_{p s}$. However, the momentum equation revealed the identity $\alpha^{\rho} \underline{v}_{t s}=\alpha^{\underline{v}} \underline{v}_{p s}$, which confirms the dependent scaling of the energy equation with $\alpha^{e}=\left(\alpha^{\underline{v}}\right)^{2} / \alpha^{\rho}$.

\subsubsection{Scaling summarised}

For isothermal cold forging processes considered here, there are seven scalar scaling factors, which are $\alpha^{1}, \alpha^{\rho}, \alpha^{\underline{v}}, \alpha^{e}, \beta, h$ and $\alpha^{\underline{u}}$. The volume, displacement, velocity and energy scaling factors are dependent scaling factors and can be calculated using the other scaling factors $\alpha^{\rho}, h$ and $\beta$, i.e. $\alpha^{1}=\beta^{-3}, \alpha^{\underline{u}}=\alpha^{\underline{v}} / h$ ( or $\alpha^{\underline{u}}=\alpha^{\rho} / h$ ), $\alpha^{\underline{v}}=h a^{\rho} / \beta$ and $\alpha^{e}=\left(\alpha^{\underline{v}}\right)^{2} / \alpha^{\rho}$. The three independent relationships $\beta, h$ and $\alpha^{\rho}$ are set in this work by: $\beta=l_{p s} / l_{t s}$, equation (5) and $\alpha^{\rho}=\rho_{t s} /\left(\beta^{3} \rho_{p s}\right)$. The choice here signifies that initial yield stresses and density of the scaled and reversed spaces are selected to match.

\section{Experimental and numerical investigations}

In order to demonstrate the application and the limitations of the finite similitude approach, cold upsetting tests were performed using two kinds of samples, i.e. cylinders and rings, which are widely used in upsetting tests to predict the flow stress and the friction coefficient for most bulk metal forming processes. These two samples were machined from the same bars of three different materials. The materials selected for the two samples are: aluminum alloy 2024-T851, copper C101 and aluminum alloy 6061-T651. Samples were prepared as full, and trial scaled materials depending upon the geometry scaling factor $\beta$. In particular, Al 2024-T851 was selected as the material for the full-scale process and was compared with the trials materials $\mathrm{Cu}-\mathrm{C} 101$ and $\mathrm{Al}$ 6061-T651, in addition to using the same material (i.e. Al 2024-T851) as a trial material. These comparisons are designed to test the scaling theory and reveal information on the procedure for designing trials to investigate the physics of a full-scale process.

A FE model was created and evaluated using the ABAQUS (explicit, version 14.3) software in order to investigate the scaling approach applied (scaled and reversed models ) to the cold upsetting tests. It is immaterial to the finite similitude theory whether an implicit or explicit solution procedure is adopted. An elastic-plastic material model is assumed and the curves presented in Fig. 2 were discretised and fed directly into ABAQUS, thus avoiding the need for the application of an approximate Holloman equation or something similar. The 
axisymmetric solid element (CAX4R) was chosen for the samples, while the axisymmetric rigid element (RAX2) was suggested for the dies. The surface to surface contact was implemented to define the contact interaction conditions between the dies and specimens. This method involves the definition of a master surface (die) and a slave surface (specimen), as reported by Hibbitt et al. (2011). A kinematic contact method was used to enforce the contact between these surfaces, which has not allowing penetration between the master and slave surfaces. A study conducted by Sofuoglu and Rasty (1999) showed that tangential and normal behaviours were demonstrated to introduce the contact properties with the friction coefficients obtained from the ring compression tests. A constant displacement was implemented in the vertical direction at the upper die reference point, while the lower die was fixed in the horizontal and vertical directions.

\subsection{Full and scaled experimental setups}

Cylindrical specimens of diameter $25 \mathrm{~mm}$ and height $25 \mathrm{~mm}$ were selected for the first case study, representing the full-scale test pieces. The geometry scaling factor $\beta$ is set to be 2 . Therefore, the dimensions of the trial-cylindrical specimens are diameter $12.5 \mathrm{~mm}$ and height $12.5 \mathrm{~mm}$. The trial and physical space specimens in their original state are depicted in Fig. 1a. All specimens in both the physical and trial space are subsequently deformed to half of their original height in an upsetting process, and their finalised geometries are depicted in Fig. 1b. The experimental tests were performed using an INSTRON-8500 machine and were carried out at room temperature.

In the second test case, ring specimens were prepared from the same bars of material used for the cylindrical tests. The dimensions of the full-scale rings are: outer diameter $25 \mathrm{~mm}$, inner diameter $12.5 \mathrm{~mm}$ and height $8.3 \mathrm{~mm}$. The geometry scaling factor $\beta$ was again set to 2 and consequently, the dimensions of the trial scaled rings are: outer diameter $12.5 \mathrm{~mm}$, inner diameter $6.25 \mathrm{~mm}$ and height $4.15 \mathrm{~mm}$. The rings were compressed to half of their original heights and are presented in Fig. 1c and 1d in their undeformed and deformed state, respectively.

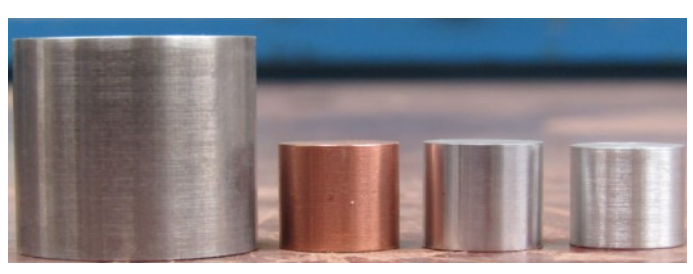

(a) Initial height of cylinders (Full and trial material models )

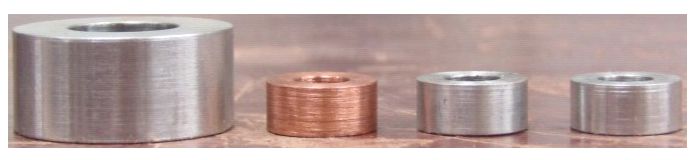

(c) Initial height of rings (Full and trial material models)

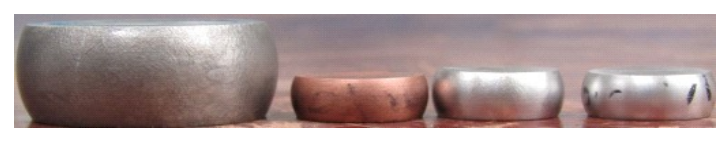

(b) $50 \%$ reductions of cylinders (Full and trial material models)

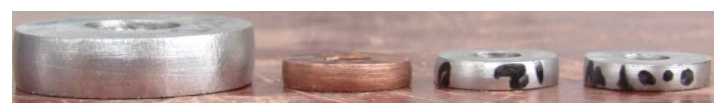

(d) $50 \%$ reductions of rings (Full and trial material models)

Fig.1. Initial and deformed samples. 
The samples (full and trial materials) and dies were cleaned before every test using acetone to remove any surface contamination. The specimens were placed between two dies of the machine and the tests were stopped when the total displacements reached to the half of the initial specimens length. A $600 \mathrm{~N}$ load cell was positioned at the crosshead to record the force. In addition, the displacement was measured depending on the movement of the crosshead of the machine. The cross-head speeds for the full-scale cylinder and ring samples (A1 2024-T851) were set to $v_{p s}=0.25 \mathrm{~mm} / \mathrm{s}$ and $0.083 \mathrm{~mm} / \mathrm{s}$, respectively. Correspondingly the cross-head speeds for the trial-scale materials (Cu-C101, Al 6061-T651 and Al 2024-T851) were obtained and set using equation (4c) (i.e. $\underline{v}_{t s}=h \beta^{-1} \underline{v}_{p s}$ ), which provides $0.10 \mathrm{~mm} / \mathrm{s}, 0.21$ $\mathrm{mm} / \mathrm{s}$ and $0.25 \mathrm{~mm} / \mathrm{s}$, respectively for cylinder samples, and $0.034 \mathrm{~mm} / \mathrm{s}, 0.074 \mathrm{~mm} / \mathrm{s}$ and $0.083 \mathrm{~mm} / \mathrm{s}$, respectively for ring samples.

\subsection{Material properties}

The quasi-static compression experiments consist of two experimental tests. As conducted by Altan and Lee (1972), the first compression test was obtained the force-displacement curves as described above. The second test was carried out to find the material properties. The second compression test was conducted on an INSTRON-8500 machine with lubricated die surfaces at a strain rate of $0.01 \mathrm{~s}^{-1}$ and at room temperature. The samples were cut to the required dimensions from the similar rods of the three materials with the diameter $8 \mathrm{~mm}$ and height $12 \mathrm{~mm}$, according to the boundary conditions of the experimental tests reported in the literature by $\mathrm{He}$ et al. (2013). At least 5 sets of tests were carried out on each material. The true stress-true strain of the aluminum alloy 2024-T851, copper C101 and aluminum alloy 6061-T651 are depicted in Fig. 2. The three materials provide (and the reason for their selection) three distinct features of strain softening, strain hardening and near perfect-plastic behaviour.

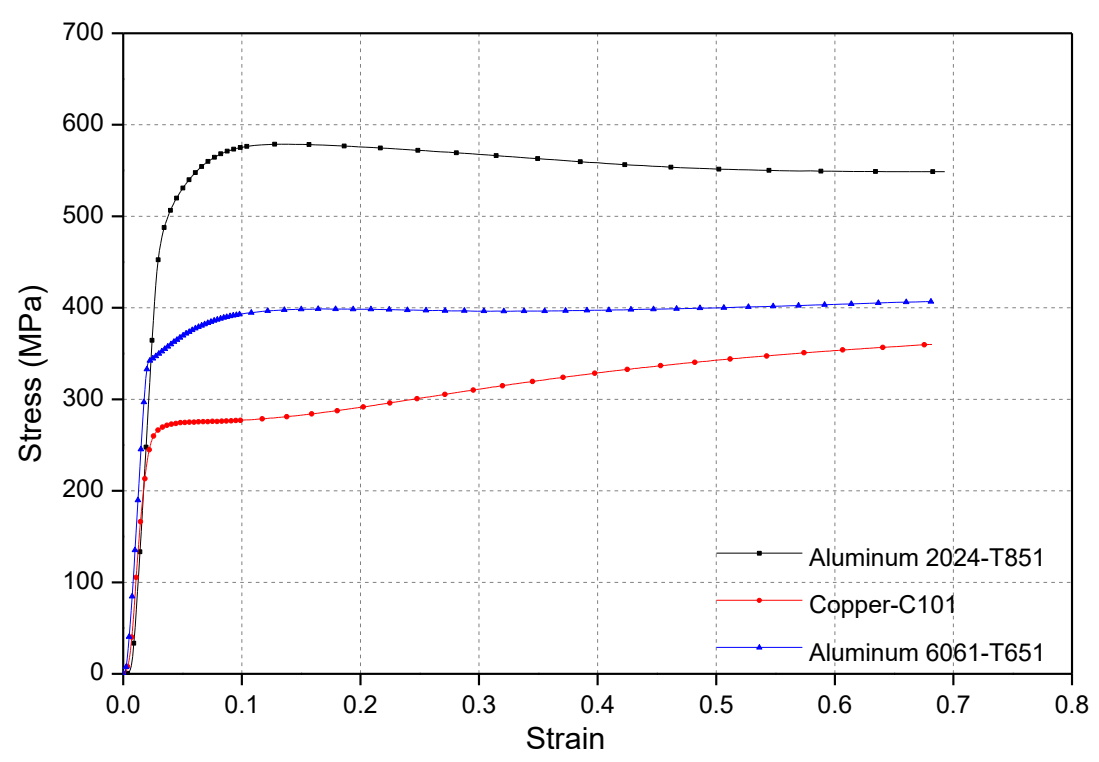

Fig. 2. True stress-true strain curves of the trial-space materials. 
It is common to represent the curves of this type using a simple equation and one possibility is the Holloman equation, which is of the form of a power-law hardening model; see for example references of Dieter Jr (1976) and Lubliner (1990). Although it is clear from Fig. 2 that softening is a feature of Al 2024-T851 it is of interest to initially explore the outcome of this approach when scaling is applied. An elastic-plastic model in the physical space would take the form

$\sigma_{p s}=\left\{\begin{array}{ccc}E_{p s} \varepsilon_{p s} & \text { if } & \varepsilon_{p s} \leq \varepsilon_{Y p s} \\ K_{p s} \varepsilon_{p s} & \text { if } & \varepsilon_{p s}>\varepsilon_{Y p s}\end{array}\right.$

where $E_{p s} \varepsilon_{Y p s}=K_{p s} \varepsilon_{Y p s}^{n_{p s}}$ for continuity, $K_{p s}$ is the material strength constant, $n_{p s}$ is the strain hardening exponent, $E_{p s}$ is Young's modulus and $\varepsilon_{Y p s}$ is the strain that signals the onset of permanent deformation.

Logarithmic strain is assumed to apply and for uniaxial compression tests and takes the form

$\varepsilon_{p s}=\left|\ln \left(\frac{l_{p s}}{l_{o p s}}\right)\right|$

where $l_{\text {ops }}$ is the original height of the specimen and the $l_{p s}$ is the height of the cylinder measured continuously from the change of the height of the specimen during the compression test.

Due to the identity Equation (4c), which for the momentum equation takes the tensorial form $\underline{\sigma}_{t s}=\alpha^{\underline{v}} h \beta^{2} \underline{\underline{\sigma}}_{p s}$ (or $\underline{\underline{\sigma}}_{t s}=\alpha^{\rho} h^{2} \beta \underline{\underline{\sigma}}_{p s}$ since $\left.\alpha^{\underline{\underline{v}}}=h a^{\rho} / \beta\right)$, it follows that finite similitude requires

$\sigma_{t s}=\left\{\begin{array}{ccc}E_{t s} \varepsilon_{t s} & \text { if } & \varepsilon_{t s} \leq \varepsilon_{Y t s} \\ K_{t s} \varepsilon_{t s}^{n_{t s}} & \text { if } & \varepsilon_{t s}>\varepsilon_{Y t s}\end{array}\right.$

where $E_{t s}=\alpha^{\rho} h^{2} \beta E_{p s}, \quad K_{t s}=\alpha^{\rho} h^{2} \beta K_{p s}, \quad \varepsilon_{t s}=\varepsilon_{p s}, \quad n_{t s}=n_{p s}$ and a similar continuity requirement $E_{t s} \varepsilon_{Y t s}=K_{t s} \varepsilon_{Y t s}^{n_{t s}}$, which flows from the previous identities.

The true stress-true strain curves of the $\mathrm{Al}$ 2024-T851, Cu-C101 and Al 6061-T651 presented in Fig. 2 yield the material properties presented in Table 1. It is clear on examination of the last column of Table 1 that exact finite similitude is not possible for the dissimilar materials considered here since $n_{t s} \neq n_{p s}$. The condition $n_{t s}=n_{p s}$ is of course satisfied if the same material is employed in both the trial and physical spaces.

Table 1. Material properties of Al 2024-T851, Cu-C101 and Al 6061-T651.

\begin{tabular}{|l|c|c|c|c|c|c|c|}
\hline \multicolumn{1}{|c|}{ Material } & $\begin{array}{c}\text { Density } \\
\left(\mathrm{kg} / \mathrm{m}^{3}\right)\end{array}$ & $\begin{array}{c}\text { Yield } \\
\text { stress } \\
(\mathrm{MPa})\end{array}$ & $\begin{array}{c}\text { Young } \\
\text { Modulus } \\
(\mathrm{MPa})\end{array}$ & $\begin{array}{c}\text { Poisson } \\
\text { ratio }\end{array}$ & $\begin{array}{c}\text { Strain } \\
\varepsilon_{Y}\end{array}$ & $\begin{array}{c}\mathrm{K} \\
(\mathrm{Mpa})\end{array}$ & $\mathrm{n}$ \\
\hline $\mathrm{Al} 2024-\mathrm{T} 851$ & 2780 & 477.3 & 69883 & 0.33 & 0.0325 & 543.7 & -0.028 \\
\hline $\mathrm{Cu}-\mathrm{C} 101$ & 8890 & 260.8 & 110507.55 & 0.31 & 0.0260 & 386.5 & 0.172 \\
\hline $\mathrm{Al} 6061-\mathrm{T} 651$ & 2710 & 352 & 61953 & 0.33 & 0.0317 & 418.0 & 0.033 \\
\hline
\end{tabular}




\subsection{Measurement of quasi-static friction coefficient}

Ring compression tests were used to determine the friction coefficient between the die and specimen. Adopting the same method proposed by Male (1964), ring samples were prepared from the bars of material based on the aspect ratio (6:3:2) in accordance with ASTM E9-09 Standard (1990). The friction is assumed to remain constant during the test and affect only the inner diameter of the ring during the deformation, which is very sensitive to the interface lubricant condition that is used in the processes. The inner diameter increases when the friction factor is sufficiently low and decreases when the it is sufficiently high. Based on this relationship, a calibration curve can be established to measure the friction coefficient factor. The ring dimensions (as stated above) of outer diameter $25 \mathrm{~mm}$, inner diameter $12.5 \mathrm{~mm}$ and height $8.3 \mathrm{~mm}$ comply with this requirement. The ring compression tests were performed using the similar testing machine (INSTRON-8500) and under dry conditions. The machine was set up to stop for every height reduction to record the change in the inner diameter and height until the reduction reaches to $50 \%$ from the height of the specimen The friction coefficients (i.e. $\mu$ values) for Al 2024-T851, Cu-C101 and Al 6061T651 were determined by using calibration curves and found to be $0.14,0.23$ and 0.15 , respectively.

\subsection{Experimental and numerical results}

In this section, three case studies are introduced which involve comparisons between experimental and numerical results to test out the new concept. Cases studies I and II relate to cold upsetting tests considering two kinds of samples (cylinder and ring) with different dimensions and three trial materials (Al 2024-T851, Cu-C101 and Al 6061-T651). The experimental and finite similitude results of the deformed shapes (cylinder and ring) of the full-scale and three half-scale trial models $(\beta=2)$ and their respective boundary conditions are shown in Fig. 3.

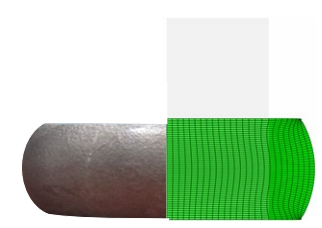

PS: Al 2024-T851

Dimensions: Dps $=25 \mathrm{~mm}$,

Lps $=25 \mathrm{~mm}$

Applied Displacement $\mathrm{U}: \mathrm{UX}=0$

$\mathrm{UY}=0, \mathrm{Uz}=12.5 \mathrm{~mm}$

Lower Die $=$ Fix

Time $=50 \mathrm{~s}$

Friction coefficient $=0.14$

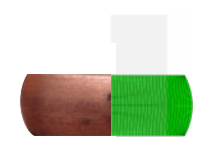

TS: $\mathrm{Cu}-\mathrm{C} 101$

Dimensions: Dts $=12.5 \mathrm{~mm}$,

Lts $=12.5 \mathrm{~mm}$

Applied Displacement $\mathrm{U}: \mathrm{Ux}=0$

$\mathrm{UY}=0, \mathrm{Uz}=6.25 \mathrm{~mm}$

Lower Die $=$ Fix

Time $=58.5 \mathrm{~s}$

Friction coefficient $=0.23$

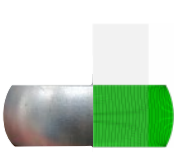

TS: Al 6061-T651

Dimensions: Dts $=12.5 \mathrm{~mm}$,

Lts $=12.5 \mathrm{~mm}$

Applied Displacement $\mathrm{U}: \mathrm{Ux}=0$,

$\mathrm{UY}=0, \mathrm{Uz}=6.25 \mathrm{~mm}$

Lower Die $=$ Fix

Time $=28.7 \mathrm{~s}$

Friction coefficient $=0.15$

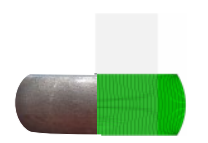

TS: Al 2024-T851 Dimensions: Dts $=12.5 \mathrm{~mm}$, Lts $=12.5 \mathrm{~mm}$

Applied Displacement $U: U x=0$, $\mathrm{UY}=0, \mathrm{Uz}=6.25 \mathrm{~mm}$ Lower Die $=$ Fix

Time $=25 \mathrm{~s}$

Friction coefficient $=0.14$ 


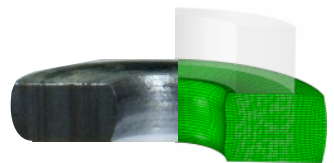

PS: Al 2024-T851

Dimensions: Dops $=25 \mathrm{~mm}$,

Dips $=12.5 \mathrm{~mm}$, Lps $=8.3 \mathrm{~mm}$

Applied Displacement U: $\mathrm{Ux}=0$,

$\mathrm{UY}=0, \mathrm{Uz}=4.15 \mathrm{~mm}$

Lower Die $=$ Fixed

Time $=50 \mathrm{~s}$

Friction Coefficient $=0.14$

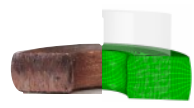

TS: $\mathrm{Cu}-\mathrm{C} 101$

Dimensions: Dots $=12.5 \mathrm{~mm}$,

Dits $=6.25 \mathrm{~mm}, \mathrm{Lts}=4.15 \mathrm{~mm}$

Applied Displacement U: $\mathrm{Ux}=0$,

$\mathrm{UY}=0, \mathrm{Uz}=2 \mathrm{~mm}$

Lower Die $=$ Fix

Time $=58.5 \mathrm{~s}$

Friction coefficient $=0.23$

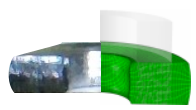

TS: Al 6061-T651

Dimensions: Dots $=12.5 \mathrm{~mm}$,

Dits $=6.25 \mathrm{~mm}, \mathrm{Lts}=4.15 \mathrm{~mm}$

Applied Displacement U: $\mathrm{Ux}=0$,

$\mathrm{UY}=0, \mathrm{Uz}=2 \mathrm{~mm}$

Lower Die $=$ Fix

Time $=28.7 \mathrm{~s}$

Friction coefficient $=0.15$

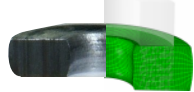

TS: Al 2024-T851

Dimensions: Dots $=12.5 \mathrm{~mm}$, Dits $=6.25 \mathrm{~mm}, \mathrm{Lts}=4.15 \mathrm{~mm}$ Applied Displacement $\mathrm{U}: \mathrm{Ux}=0$, $\mathrm{UY}=0, \mathrm{Uz}=2 \mathrm{~mm}$

Lower Die $=$ Fix

Time $=25 \mathrm{~s}$

Friction coefficient $=0.14$

(b)

Fig.3. Observed and predicted geometry for deformed cylinders (a) and rings (b).

\subsubsection{Scaling of cylinder samples}

As mentioned above, the Al 2024-T851 cylinder is used for the full-scale process and $\mathrm{Cu}-\mathrm{C101}$, Al 6061-T651 and Al 2024-T851 are chosen as trial material models. Since the deformation process is a cold process, there are 7 scalar parameters involved, which are: $\beta$, $\alpha^{1}, \alpha^{\rho}, h, \alpha^{e}, \alpha^{\underline{v}}$ and $\alpha^{\underline{u}}$. Recall (see Davey et al. (2017) and Section 2 ) that these parameters can be divided into independent $\left(\beta, \alpha^{\rho}\right.$ and $\left.h\right)$ and dependent scaling parameters $\left(\alpha^{1}, \alpha^{e}, \alpha^{\underline{v}}\right.$ and $\left.\alpha^{\underline{u}}\right)$. The scaling parameter values for full scale (A1 2024-T851) and trial scaled materials (Cu-C101, Al 6061-T651 and Al 2024-T851) are presented in Table 2.

Table 2. Scaling parameters for full and trial material models.

\begin{tabular}{|l|l|c|c|c|c|c|}
\hline Model & $\begin{array}{l}\text { Trial Space } \\
\text { Material }\end{array}$ & $\alpha^{\rho}$ & $h$ & $\alpha^{e}$ & $\alpha^{\underline{\underline{v}}}$ & $\alpha^{\underline{u}}$ \\
\hline Trial I & Cu-C101 & 0.4 & 0.85 & 0.072 & 0.170 & 0.199 \\
\hline Trial II & $\mathrm{Al} \mathrm{6061-T651}$ & 0.121 & 1.74 & 0.093 & 0.106 & 0.0600 \\
\hline Trial III & Al 2024-T851 & 0.125 & 2 & 0.125 & 0.125 & 0.0625 \\
\hline
\end{tabular}

One of the features of the new scaling theory is the ability to scale in two directions, i.e. direct scaling from the physical to the trial space and reverse scaling from the trial to the physical space. This feature allows comparisons to be performed in either space and to test for example how a trial space material performs in capturing the process as measured in the physical space. The choice of independent scalar factors provides different possibilities for matching material properties that remain fixed with regard to direct and reverse scaling. The scaling geometry factor $\beta$ is fixed in this study leaving only two independent scaling 
parameters to be selected, i.e. 2 degrees of freedom. In this process, density and yield stress are identified to be matched in both scaling for each trial material. For example, the yield stress of the reversed trial material $(\mathrm{Cu}-\mathrm{C} 101)$ is equal to yield stress of the full-scale material (Al 2024-T851), and similarly for density. The material properties and the power-law coefficients (supplied for interest) for the reversed and scaled models are shown in Table 3. Note that the data in this table pertains to virtual materials in the trial space (i.e. scaled model) and physical space (i.e. reversed model). Thus, for example, "Reversed Trial I" involves the projection of the trial material $\mathrm{Cu}-\mathrm{C101}$, with the objective of matching the physical material Al 2024-T851. Examination of Table 3 and Table 1 reveals that yield stress and density of the reversed virtual material matches with Al 2024-T851 as expected and dictated by the fixing of the scaling parameters. The virtual models can be contrasted against real physical models as illustrated by the schematic diagram in Fig 4.

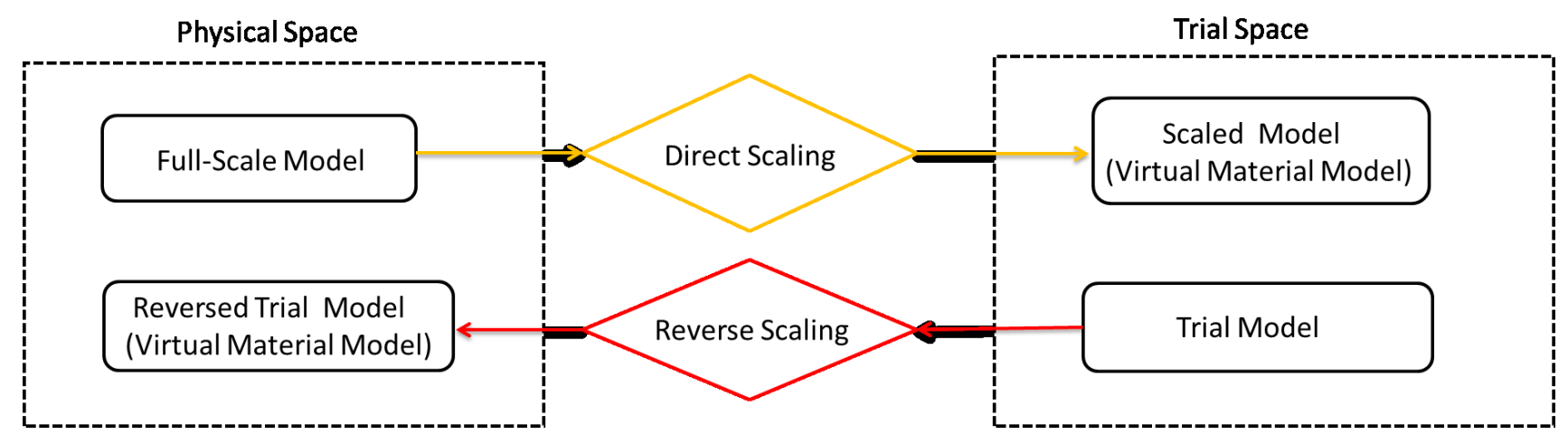

Fig. 4. Sketch for the procedure of the direct and reverse scaling, based on the experimental results of the full and trial models.

The results for force-reduction in height and the change in diameter of the physical and three trial models are presented in Figs. 5 and 6, respectively.

Table 3. Material constants for reversed and scaled models.

\begin{tabular}{|c|c|c|c|c|c|c|}
\hline Model & Material & $\begin{array}{c}\text { Yield stress } \\
(\mathrm{MPa})\end{array}$ & $\begin{array}{c}\text { Density } \\
\left(\mathrm{kg} / \mathrm{m}^{3}\right)\end{array}$ & $\begin{array}{c}\text { Young's } \\
\text { Modulus } \\
(\mathrm{MPa})\end{array}$ & $\begin{array}{c}\mathrm{K} \\
(\mathrm{MPa})\end{array}$ & $\mathrm{n}$ \\
\hline Reversed Trial I & Cu-C101 & 477.3 & 2780 & 189403 & 992.45 & 0.172 \\
\hline Scaled I & Al 2024-T851 & 260.8 & 8890 & 40773.37 & 216.18 & -0.028 \\
\hline Reversed Trial II & Al 6061-T651 & 477.3 & 2710 & 94699.41 & 784.67 & 0.033 \\
\hline Scaled II & Al 2024-T851 & 352 & 2780 & 51569.84 & 308.46 & -0.028 \\
\hline Reversed Trial III & Al 2024-T851 & 477.3 & 2780 & 69883 & 579.05 & -0.028 \\
\hline Scaled III & Al 2024-T851 & 477.3 & 2780 & 69883 & 579.05 & -0.028 \\
\hline
\end{tabular}


It is apparent from these results that the reversed trial material (Al 2024-T851) provides excellent agreement with the results of the full-scale model. In this particular case, the maximum divergence in the ultimate loads between the full-scale (Al 2024-T851) and the reversed trial material (Al 2024-T851) is $1.81 \%$ (see Fig. 5c). This divergence is noticeably increased when the other reversed trial material models (Cu-C101 and Al 6061-T651) are used, being the maximum differences of $5.10 \%$ and $4.03 \%$ for copper $\mathrm{C} 101$ and aluminum 6061-T651, respectively (see Figs 5a and 5b). These divergences were markedly less at the yield point as might be expected since scalars were selected to match the yield stress. In addition, the results of the direct scaled model (A1 2024-T851) which were obtained by direct scaling are shown in Figs. 5. As can be seen, the scaled full scale (Al 2024-T851) has the ability to reveal almost perfect results with the same trial material and excellent results for Al 6061-T651 (see Figs. 5a and 5b), except the results of the trial model made of copper$\mathrm{C} 101$. Some differences can be seen between the trial material (Cu-C101) and scaled material model (Al 2024-T851). For instance, in the case of the trial material models made of $\mathrm{Cu}$ $\mathrm{C} 101$ and $\mathrm{Al}$ 6061-T651, the maximum divergence in the ultimate loads are $3.08 \%$ and $2.78 \%$ respectively, while this divergence is only $1.65 \%$, for trial model made of Al 2024$\mathrm{T} 851$.

Fig. 6, presents the change in the meridian circle radius $\left(R_{0}\right)$ of the full-scale (Al 2024-T851) and the corresponding reversed trial material models values predicted from the trial material models (Cu-C101, Al 6061-T651 and Al 2024-T851). It is found that the most significant deviations are $1.46 \%$ and $0.058 \%$ when the trial material models are made of $\mathrm{Cu}-\mathrm{C} 101$ and Al 6061-T651 (see Fig. 6a and 6b). This deviation becomes smallest if Al 2024-T861 is taken as a trial material model which is less than $0.017 \%$ (see Fig. 6c).

The contour plot of equivalent plastic strain distribution for the cylinder for the full and scaled model is shown in Fig. 7. All the contour plots have the same scales in the full and scaled models. Strain being dimensionless is required to be identical for finite similitude theory in both the physical and trial spaces. Fig. 8 shows the comparison between the equivalent plastic strain for the cylinder over the meridian circle radius for the full-scale model (Al 2024-T851) and the three trial materials at the corresponding times, $t=50 \mathrm{~s}$, $\tau_{C u}=58.5 \mathrm{~s}, \tau_{A 16061}=28.7 \mathrm{~s}$ and $\tau_{A 12024}=25 \mathrm{~s}$ where $\tau=t / h$. It can be seen from the results of the reversed models that the equivalent plastic strain for trial material $\mathrm{Cu}-\mathrm{C} 101$ is slightly higher than the reversed trial materials Al 2024-T851 and Al 6061-T651. The difference is expected and is a direct consequence of the higher friction coefficient involved with the upsetting of $\mathrm{Cu}-\mathrm{C} 10$. 

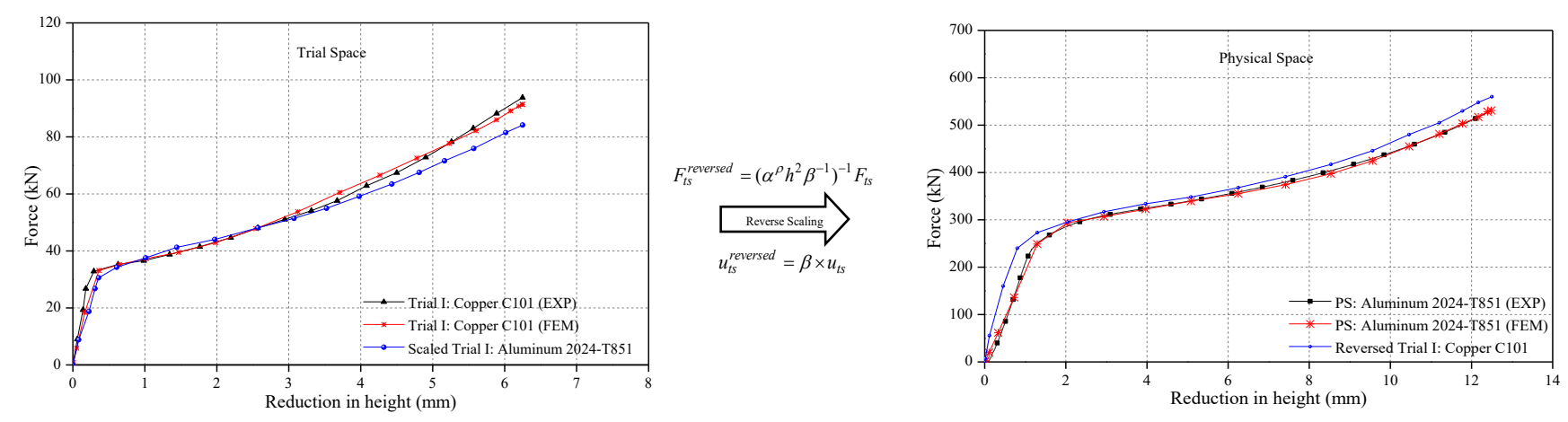

(a)
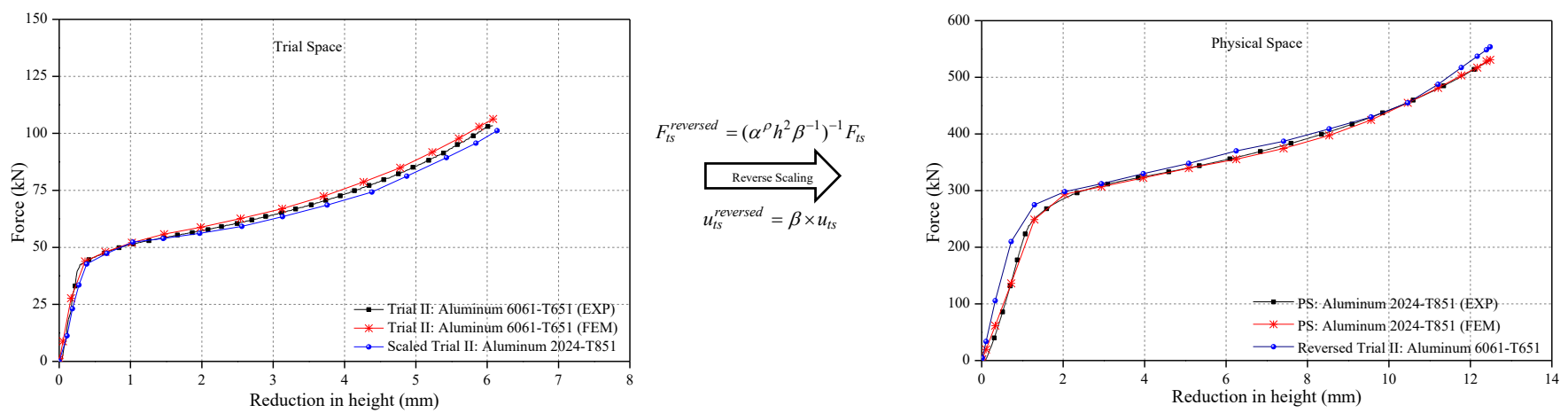

(b)
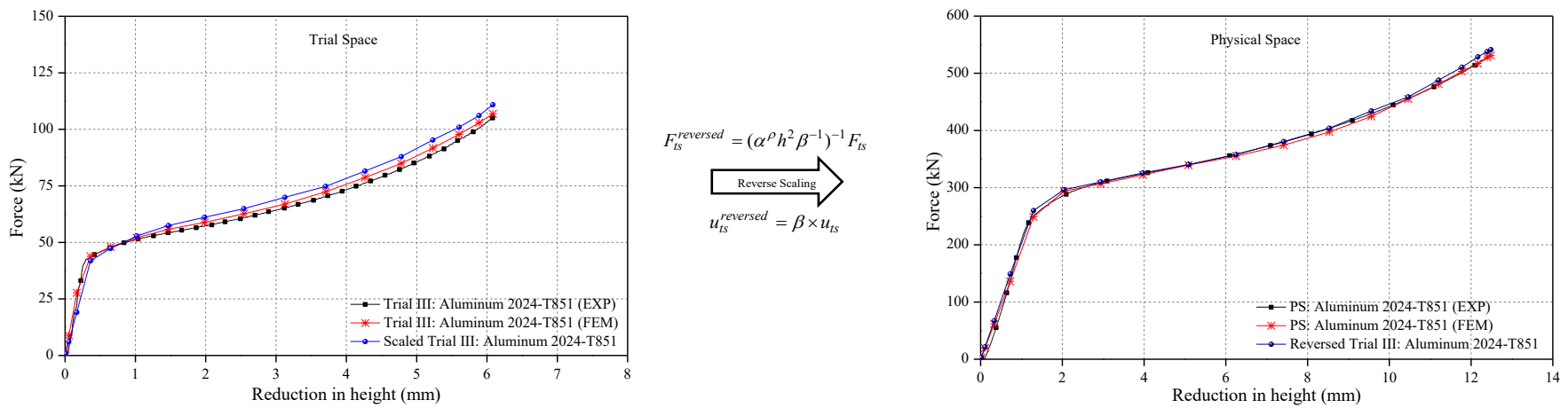

(c)

Fig. 5. Experimental and numerical results for force-reduction in height in the physical and trial spaces. 

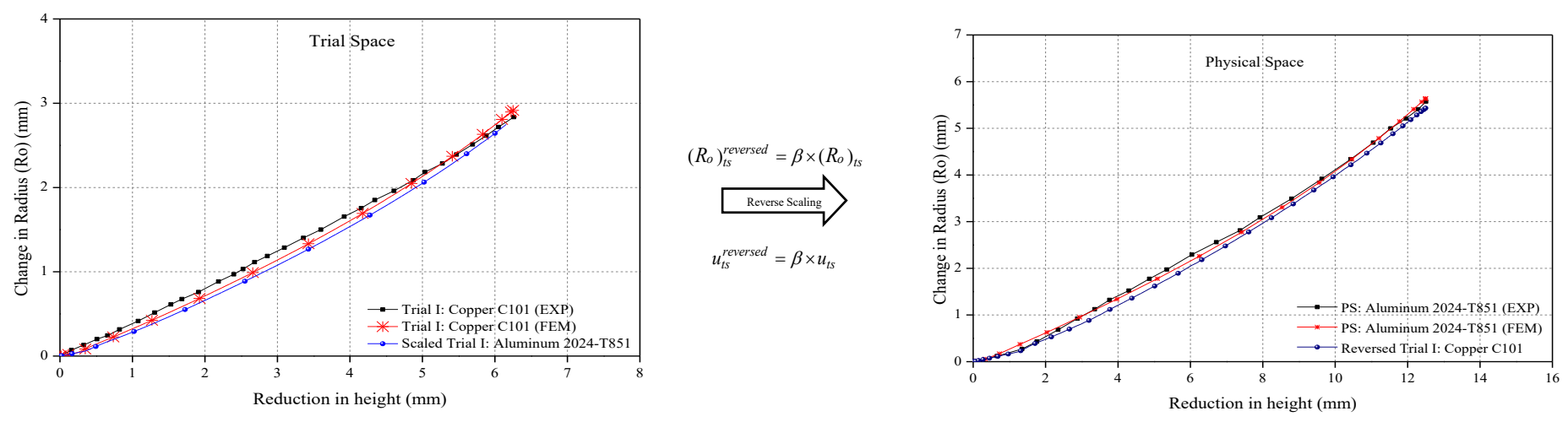

(a)
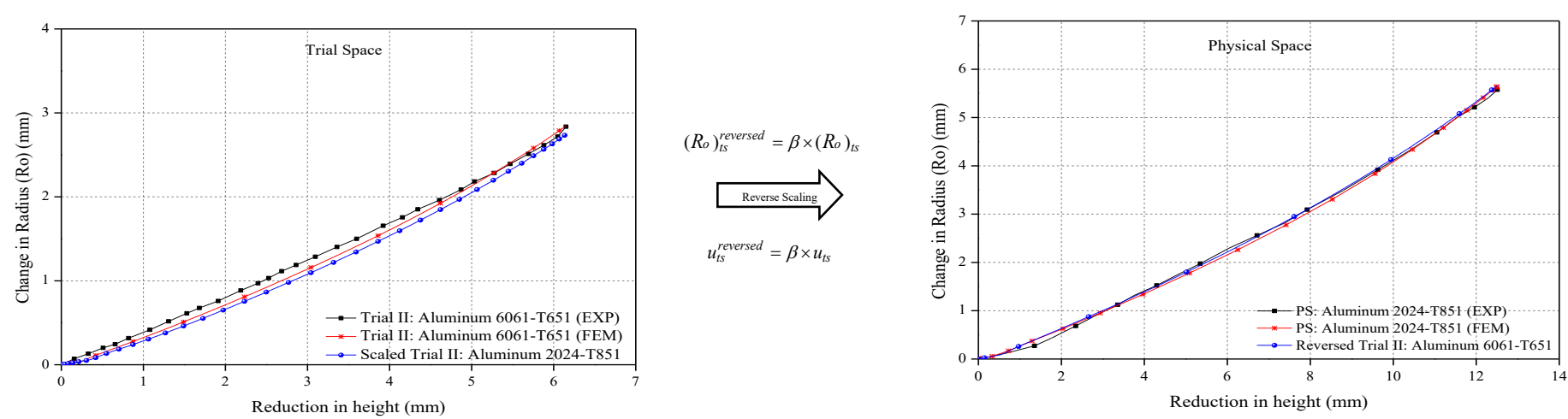

(b)
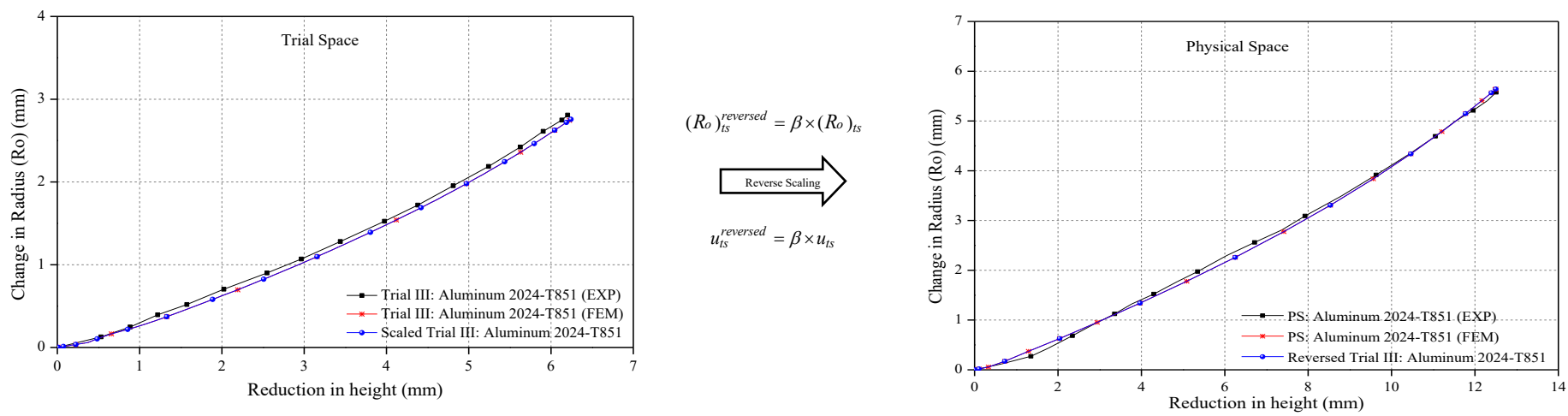

(c)

Fig. 6. Experimental and numerical results for change in meridian radius in the physical and trial spaces. 


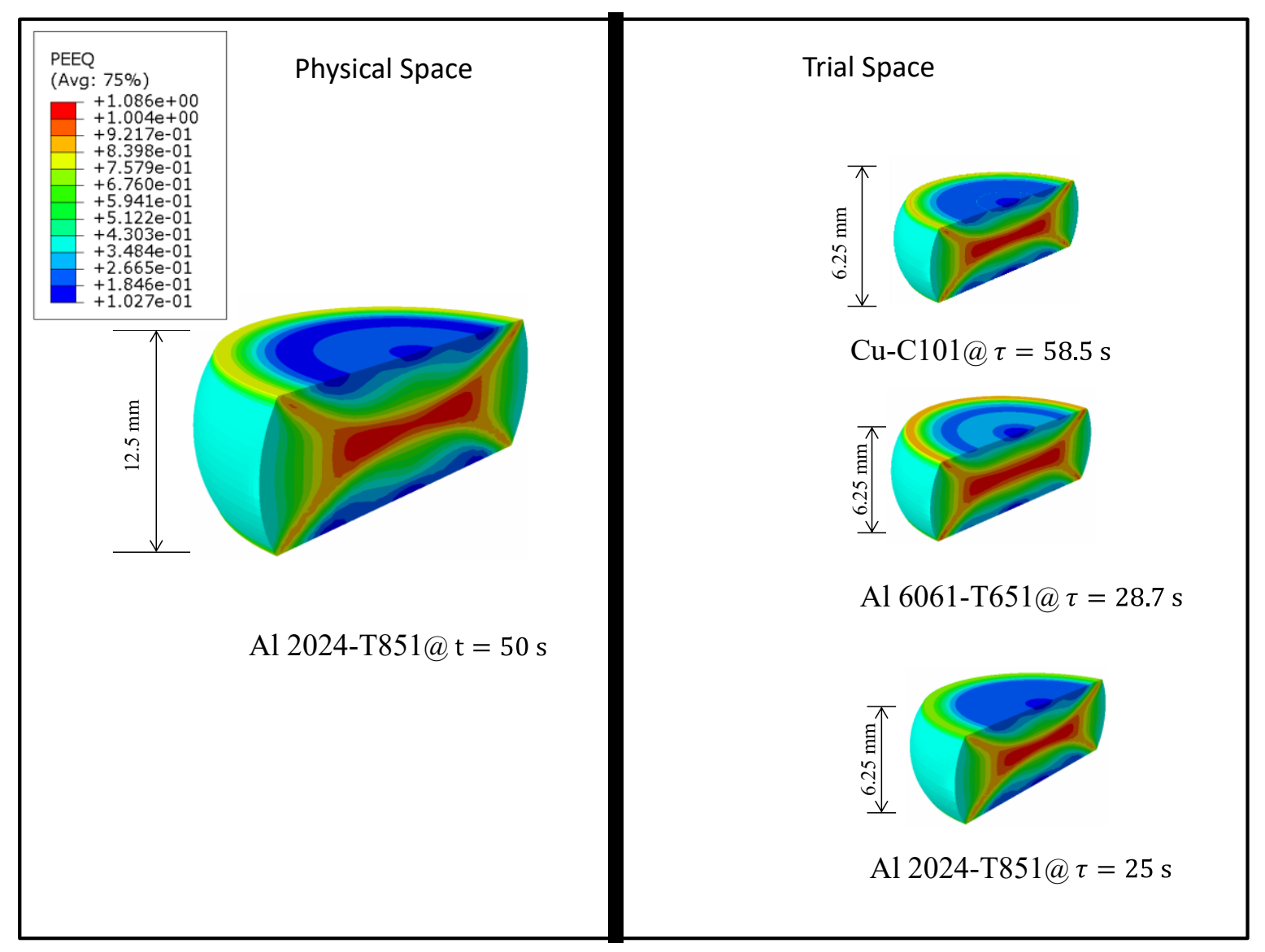

Fig. 7. Equivalent plastic strain distribution of cylindrical samples in physical and trial spaces. 

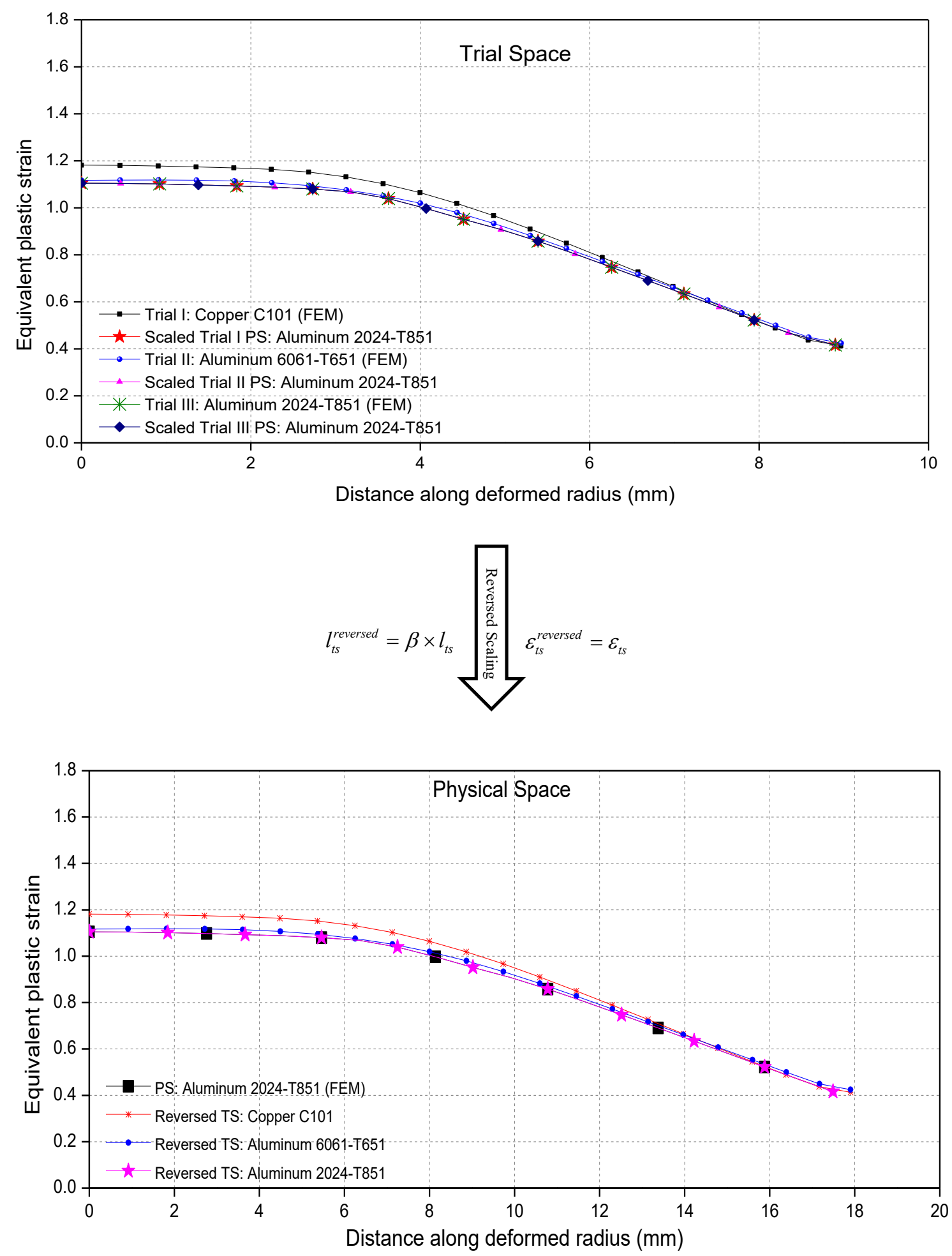

Fig. 8. Equivalent plastic strain of cylinders over meridian radius for physical and trial models. 


\subsubsection{Scaling of the ring samples}

In this case, the novel concept of finite similitude has been tested by using ring samples (full and trial materials). Again Al 2024-T851 was used as the full-scale model and $\mathrm{Cu}-\mathrm{C101}, \mathrm{Al}$ 6061-T651 and Al 2024-T851 were considered as the trial material models. The scaling factors of the physical and trial materials along with the material properties of the reversed and scaled experimental results are the same as those used in the previous section (Section 3.4.1). The results of force-reduction in height and change in radius of the physical and trial models are shown in Figs. 9 and 10, respectively. It is clear from the results that reversed trial materials (Cu-C101 and Al 6061-T651) display significant deviations with the results of the full-scale model (Al 2024-T851), except for results close to the yield point (see Figs. 9a and $\mathrm{b}$ ). The maximum divergences of ultimate loads for reversed trial material $(\mathrm{Cu}-\mathrm{C} 101$ and Al 6061-T651) are $7.98 \%$ and $6.32 \%$, respectively. These large deviations are essentially absent if Al 2024-T851 is used as a trial material, where the maximum error is less than $2.15 \%$ (see Fig. 9c). In addition, the results of the direct scaled model (Al 2024-T851) are shown in Fig. 9. As can be seen, the errors are quite significant when compared with the trial models made of $\mathrm{Cu}-\mathrm{C} 101$ and $\mathrm{Al}$ 6061-T651. On the other hand, these errors are significantly less when compared with the same material (Al 2024-T851). For instance, the maximum divergence in the ultimate loads between the direct scaled (Al 2024-T851) and trial material models (Cu-C101 and $\mathrm{Al} 6061-\mathrm{T} 651)$ are $9.68 \%$ and $6.96 \%$ for a model scaled by $\beta=2$. Also, these deviations are drastically reduced when comparing the scaled material model with the same material, where the divergence is only $2.55 \%$. Fig. 10 shows how the radius difference $R_{o}-R_{i}$ changes for the meridian circle with reduction in billet height for all reversed trial materials (Cu-C101, Al 6061-T651 and Al 2024-T851). Good accuracy is recorded with the corresponding experimental results of the full-scale model with maximum errors less than $2.60 \%, 2.15 \%$ and $1.27 \%$, respectively. The contour plot of equivalent plastic strain distribution for the ring for the full and scaled model is shown in Fig. 11. It should be mentioned here the strain being dimensionless is identical in the full and scaled models. The comparison between the equivalent plastic for the full-scale and three trial material models at the same corresponding time of the cylinders is shown in Fig. 12. It is apparent from the results that the reversed trial material (Al 2024-T851) provides good results for a description of the full-scale model. 

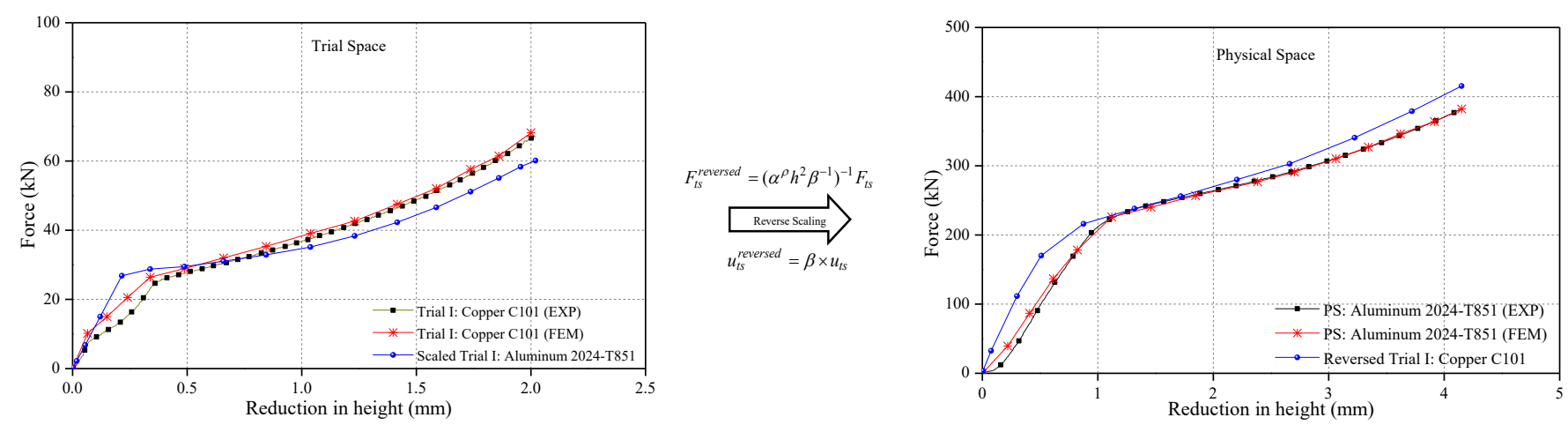

(a)
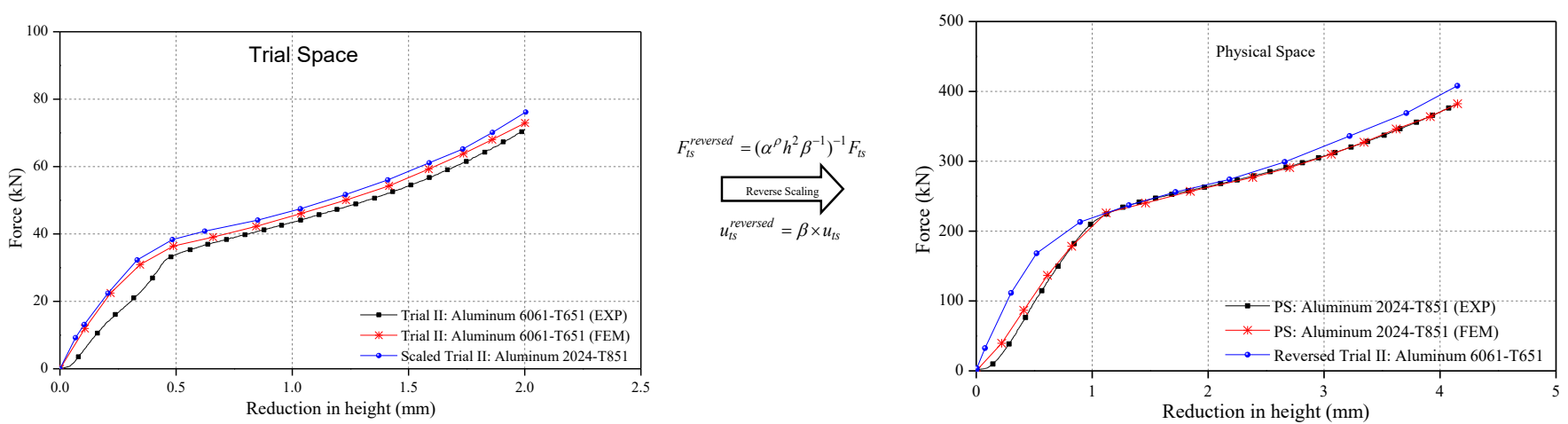

(b)
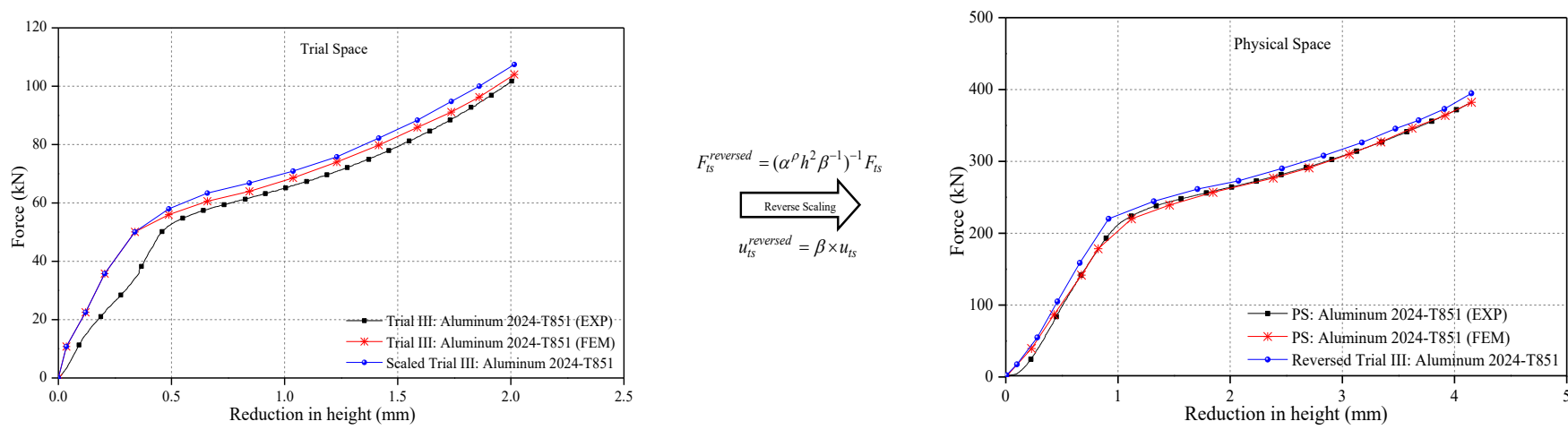

(c)

Fig. 9. Experimental and numerical results for force-reduction in height in the physical and trial spaces. 


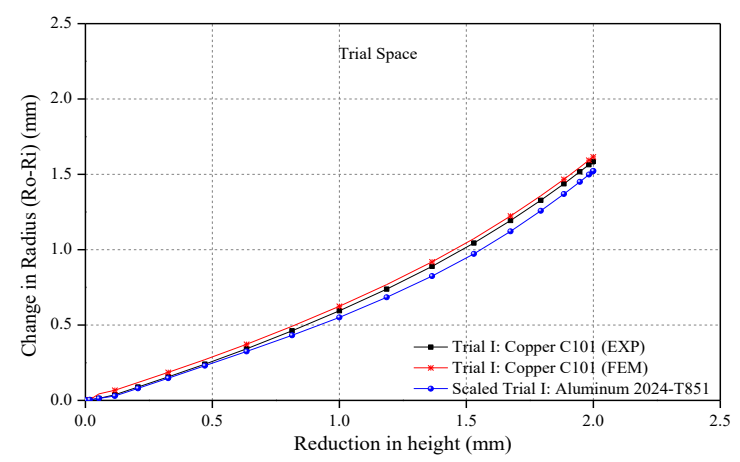

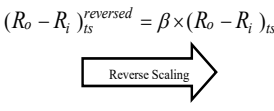

$u_{t s}^{\text {reversed }}=\beta \times u_{t s}$

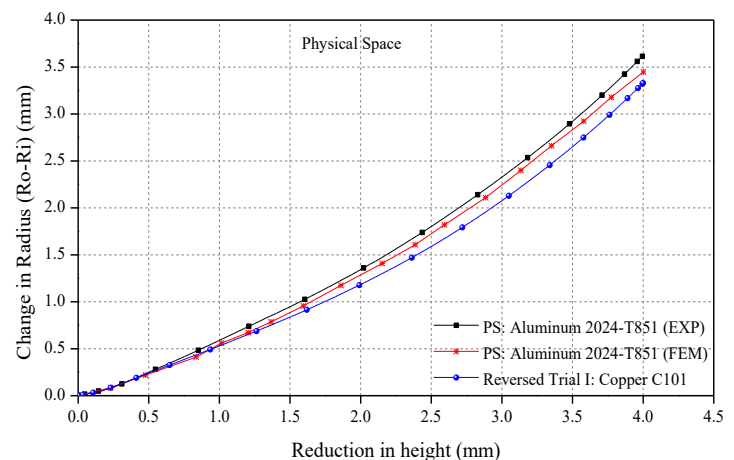

(a)

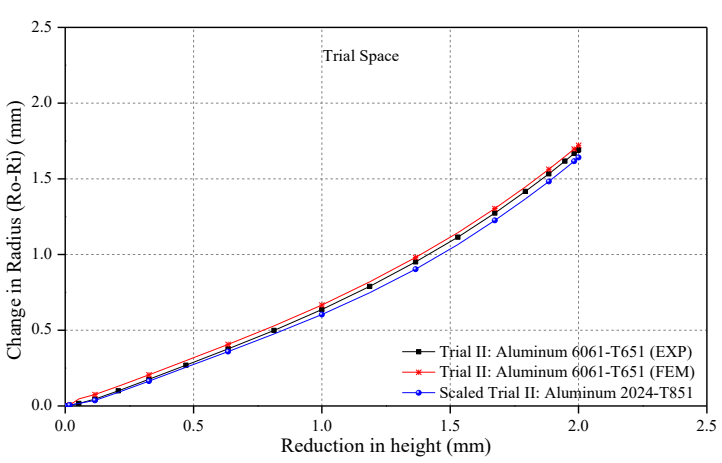

$\left(R_{o}-R_{i}\right)_{t s}^{\text {reversed }}=\beta \times\left(R_{o}-R_{i}\right)_{t s}$
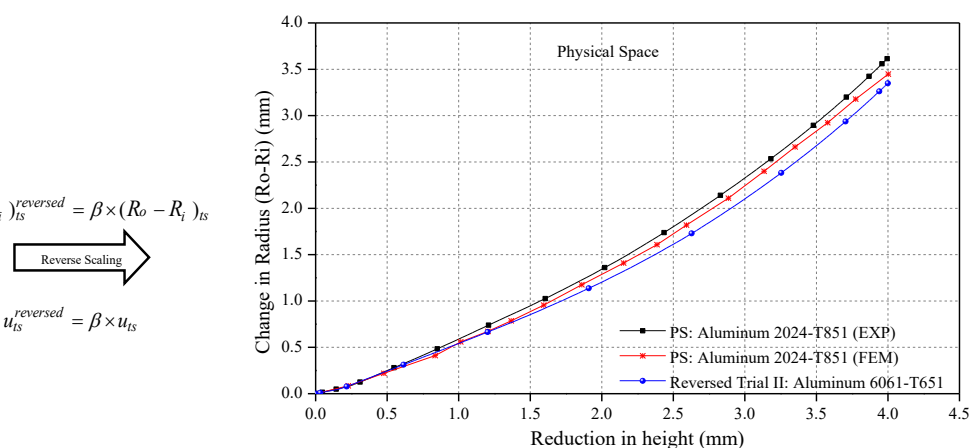

(b)

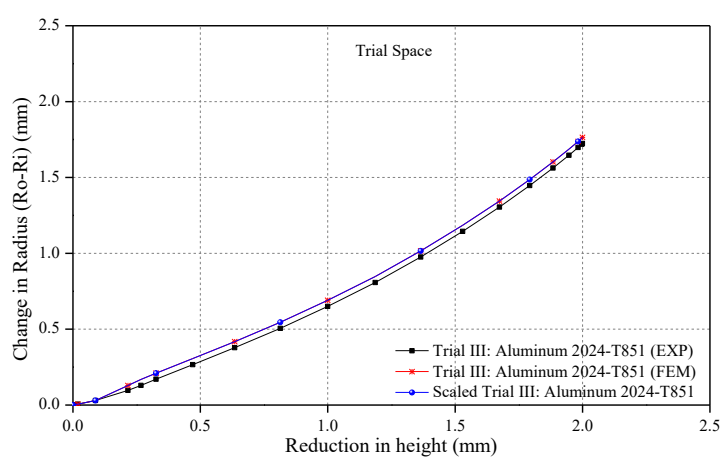

$\left(R_{o}-R_{i}\right)_{t s}^{\text {reversed }}=\beta \times\left(R_{o}-R_{i}\right)_{t s}$

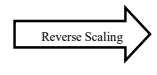

$u_{t s}^{\text {reversed }}=\beta \times u_{t s}$

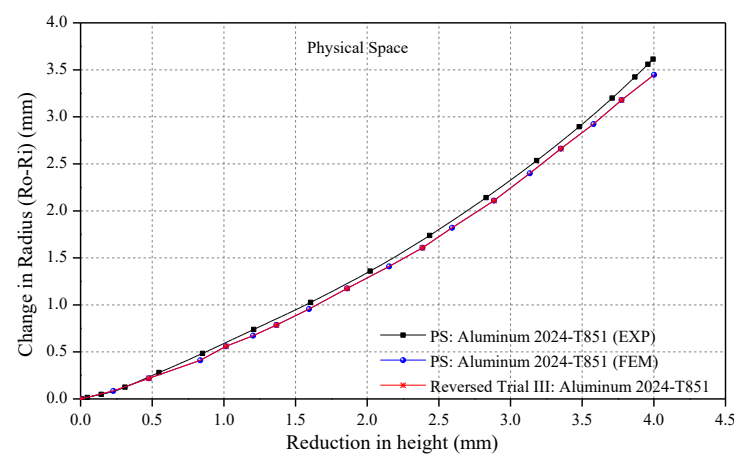

(c)

Fig. 10. Experimental and numerical results for $R_{o}-R_{i}$ of the meridian circle in the physical and trial spaces. 


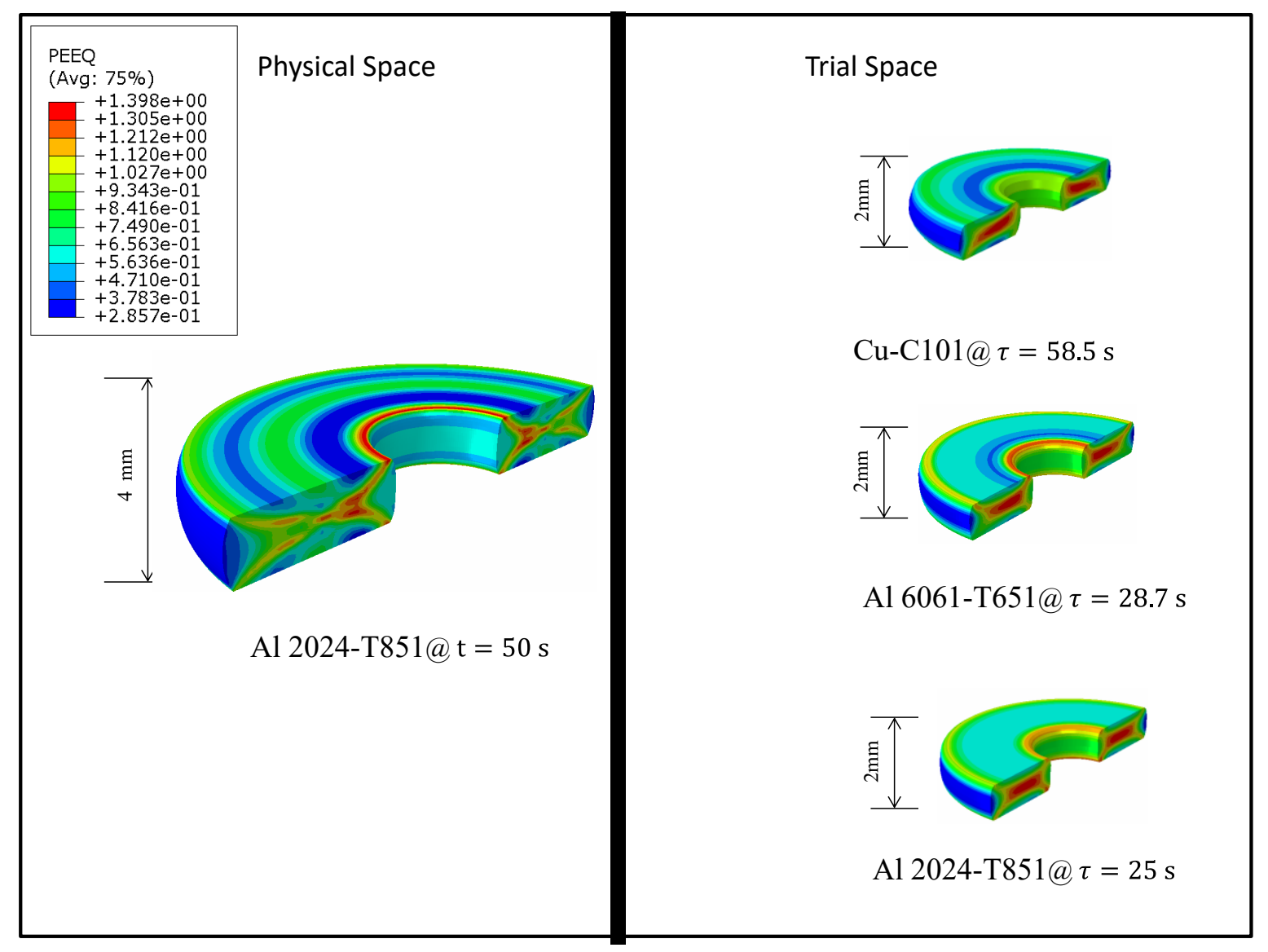

Fig.11. Equivalent plastic strain distribution of ring samples in physical and trial spaces. 

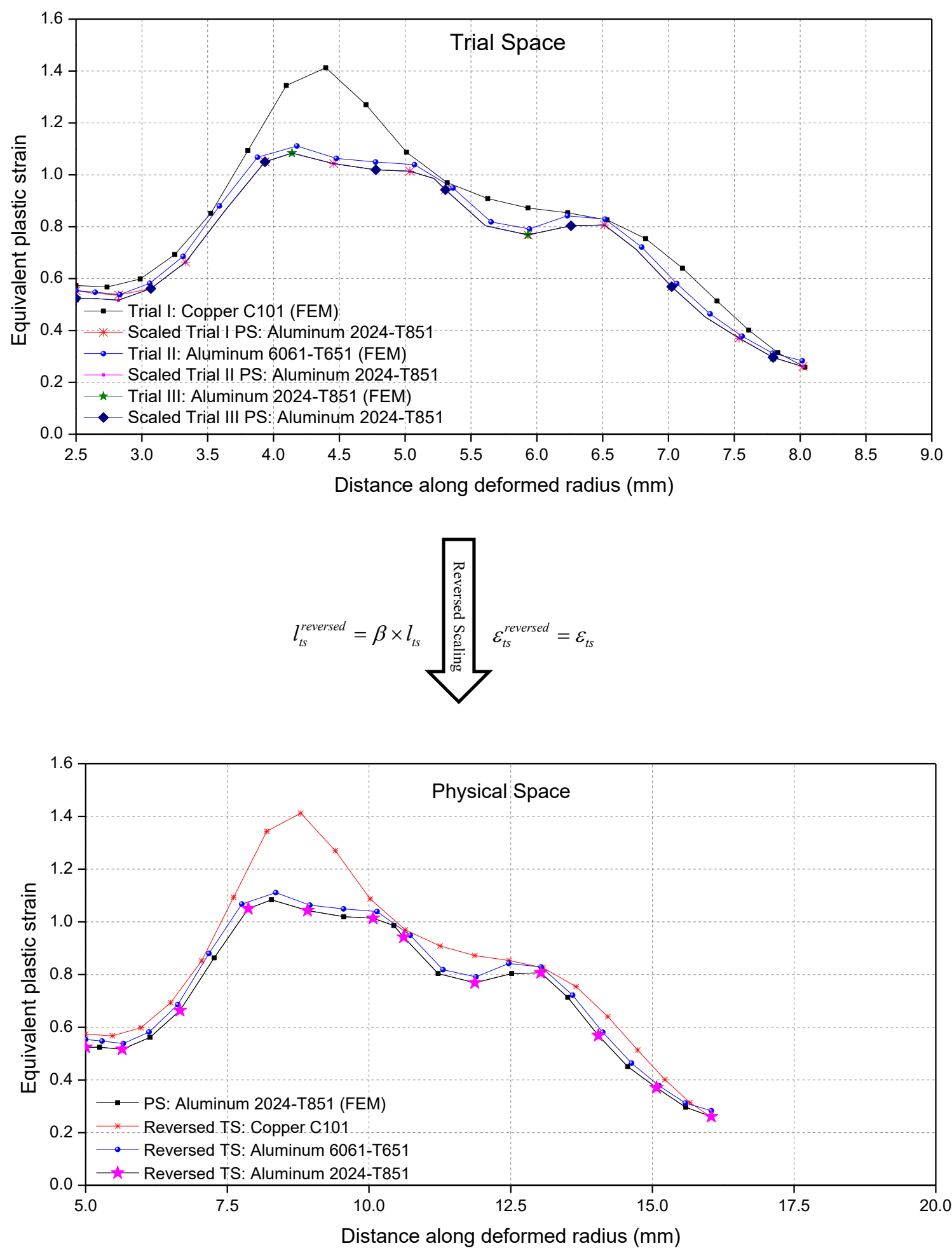

Fig.12. Equivalent plastic strain of rings over meridian radius for physical and trial models. 
The results of Case I and II indicate that the use of an identical trial and physical materials (Al 2024-T851) can provide good results compared with alternative trial materials (e.g. Cu$\mathrm{C} 101$ and $\mathrm{Al}$ 6061-T651 in this case). The mismatch in results for the dissimilar materials was somewhat anticipated by the analysis performed in Section 3, since $n_{t s} \neq n_{p s}$ although the extent is now revealed in Fig. 5 and 9. For instance, in the case of trial material model $(\mathrm{Cu}-$ $\mathrm{C} 101$ ), the reversed stress-strain curve is always higher than other trial material models (Al 6061-T651 and Al 2024-T851) curves, generating higher loads for both cylinder and ring samples (see Fig 13). On the other hand, for both trial material models Al 6061-T651 and Al 2024-T851, the close results obtained at full-scale reflect the proximity of the trial material curves. The more significant errors presented in Fig. 9 can be attributed to friction and the dissimilar coefficients of friction employed. The coefficient of friction is a dimensionless quantity and as such is invariant in the scaling process. As stated in Altan and Lee (1972), at higher friction, a conical dead metal zone develops and metal flow localizes mostly by "rolling" on the corners of the sample being tested. This leads to higher metal flow and interface friction between the die and sample leading to greater frictional dissipation and a total increase the upsetting energy resulting in a higher upsetting load. In addition, the friction shear stress tends to increase with increasing strain hardening of the metal flow. These two results have an impact on the upsetting load. It is evident that the selection of trial material is important on the extent to which a scaled design satisfies similitude. Also, the boundary conditions such as the impact of friction must be taken into consideration; this effect is considered again in the following case study.

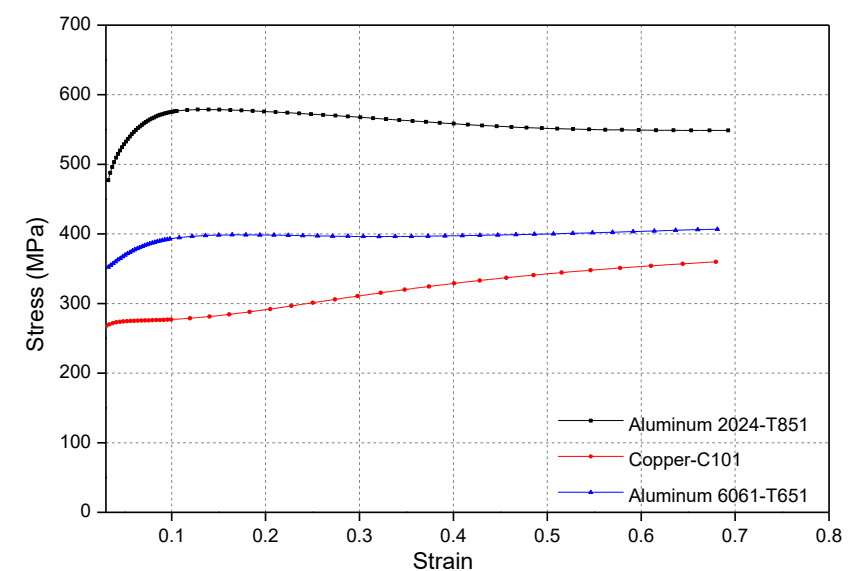

(a) Quasi-static material curves

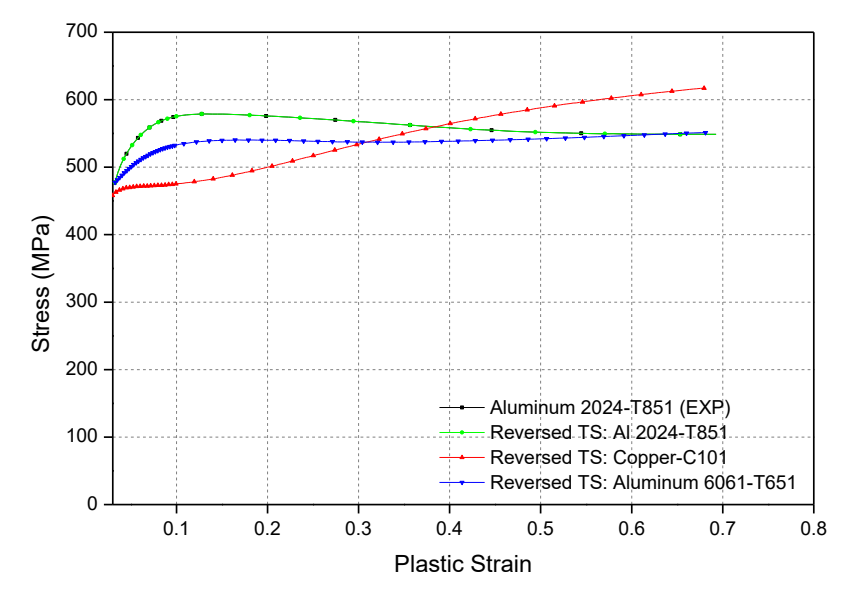

(b) Quasi-static material curves when scaled by finite similitude method

Fig.13. Stress-Strain curves for properties listed in Tables 1 and 3. 


\section{Analytical investigation}

Analytical solutions exist for the upsetting of cylinders and rings and it is of some interest to investigate the effect scaling has on these solutions. As pointed out by Dieter et al. (2003), Hosford and Caddell (2011), forging force can be readily obtained by application of a slab method and on the neglect of bulging. A linearized Coulomb friction model is assumed to apply to describe the friction behaviour. The forging loads for the cylinder and ring in the physical space is provided by the respective equations

$$
F_{p s}=\sigma_{p s} A_{p s}\left(1+\frac{1}{3} \mu_{p s} \frac{D_{p s}}{H_{p s}}\right)
$$

and

$$
F_{p s}=\sigma_{p s} A_{p s}\left(1+\frac{1}{2} \frac{\mu_{p s}}{H_{p s}}\left(R_{0 p s}-R_{i p s}\right)\right)
$$

where $A_{p s}$ is a current area, $\mu_{p s}$ is the Coulomb coefficient of friction, $D_{p s}$ is the current diameter of the sample, $H_{p s}$ is the current height of the sample, $R_{o p s}$ is the outer radius, $R_{i p s}$ is the inner radius and $\sigma_{p s}$ is the flow stress which can be replaced using Holloman's equation (see Section 3.2). As discussed by Vansant (1967), equations (8) and (9) can be simplified to a single variable of the current height $\left(H_{p s}\right)$, assuming constancy of material volume for plastic deformation (i.e. $A_{p s} H_{p s}=A_{0 p s} H_{0 p s}$ ), and position of the neutral radius (i.e. $\left.R_{p s}=\left(R_{0 p s}+R_{i p s}\right) / 2\right)$. A similar procedure applied to the trial space by subscript $p s$ replaced by $t s$, which gives

$$
F_{t s}=\sigma_{t s} A_{t s}\left(1+\frac{1}{3} \mu_{t s} \frac{D_{t s}}{H_{t s}}\right)
$$

and

$$
F_{t s}=\sigma_{t s} A_{t s}\left(1+\frac{1}{2} \frac{\mu_{t s}}{H_{t s}}\left(R_{0 t s}-R_{i t s}\right)\right)
$$

The reverse scaling of applied force for the cylinder and ring is readily formulated from the identity $\underline{\underline{\sigma}}_{t s}=\alpha^{\rho} h^{2} \beta_{\underline{\sigma}_{p s}}$, which provides,

$$
F_{t s}^{\text {reversed }}=\left(\alpha^{\rho} h^{2} \beta^{-1}\right)^{-1} F_{t s}
$$

Similarly, the direct scaled relationship for both the cylinder and ring is

$$
F_{p s}^{\text {scaled }}=\left(\alpha^{\rho} h^{2} \beta^{-1}\right) F_{p s}
$$

where with exact finite similitude $F_{p s}^{\text {scaled }}=F_{t s}$ and $F_{t s}^{\text {reversed }}=F_{p s}$ for both the rings and cylinders. However, inspection of Equations (8) to (10) reveals that exact matching is only possible with $\sigma_{t s}=\alpha^{\rho} h^{2} \beta \sigma_{p s}$ and $\mu_{p s}=\mu_{t s}$. In order to investigate the errors involved the scaling 
parameters adopted in Case-Study I are used in this analysis. The results for force against reduction in height (i.e. $H_{0}-H$ ) for the physical and trial space models of cylinders and rings are depicted in Figs. 14 and 15, respectively. It can be seen that the scaling theory predicts to a reasonable accuracy the results of the experimental and analytical solutions. The corresponding average errors for the ultimate loads for the reversed trial experiments $(\mathrm{Cu}-$ $\mathrm{C} 101, \mathrm{Al} 6061-\mathrm{T} 651$ and $\mathrm{Al} 2024-\mathrm{T} 851$ ) of the cylinders are respectively $8.36 \%, 5.67 \%$ and $4.27 \%$. Similarly, the percentages for the rings are $13.71 \%, 10.11 \%$ and $5.37 \%$. These results confirm that the finite similitude concept can equally be applied to analytical expressions for analysis purposes. 

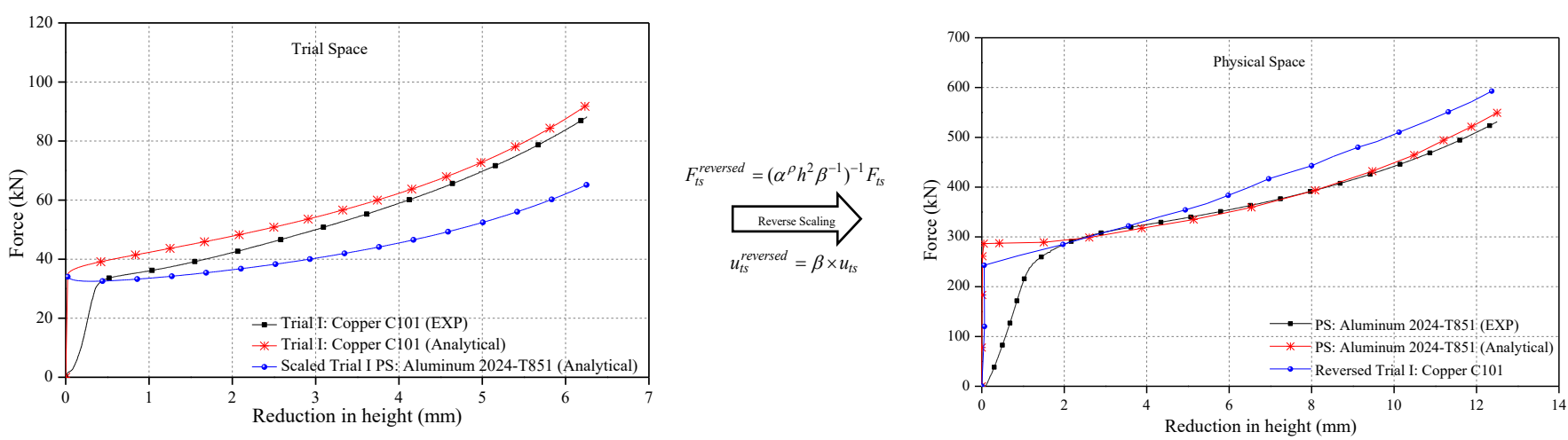

(a)
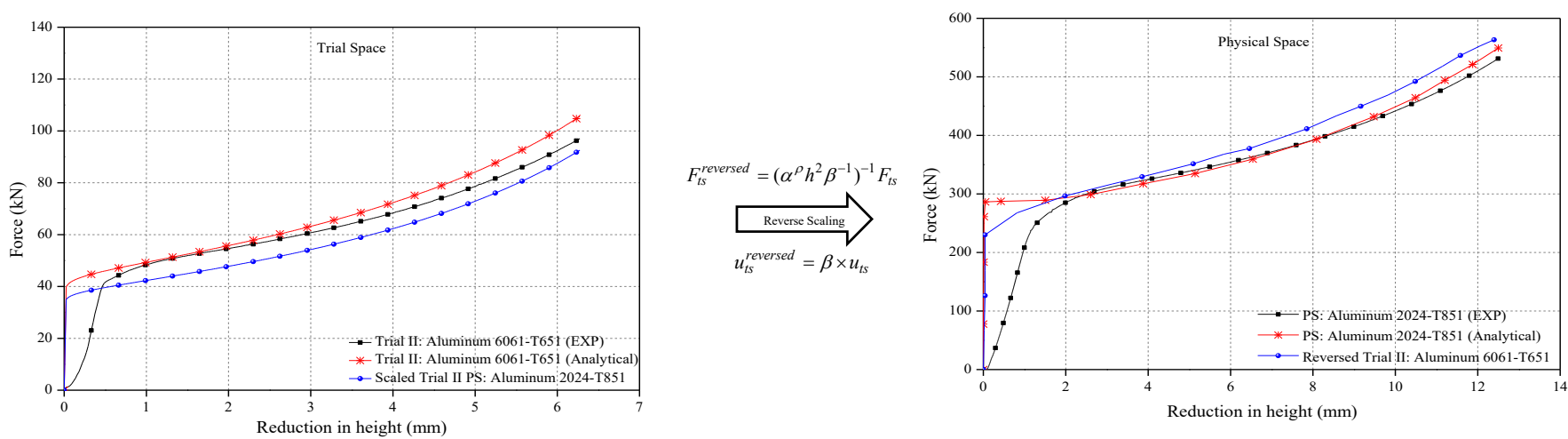

(b)
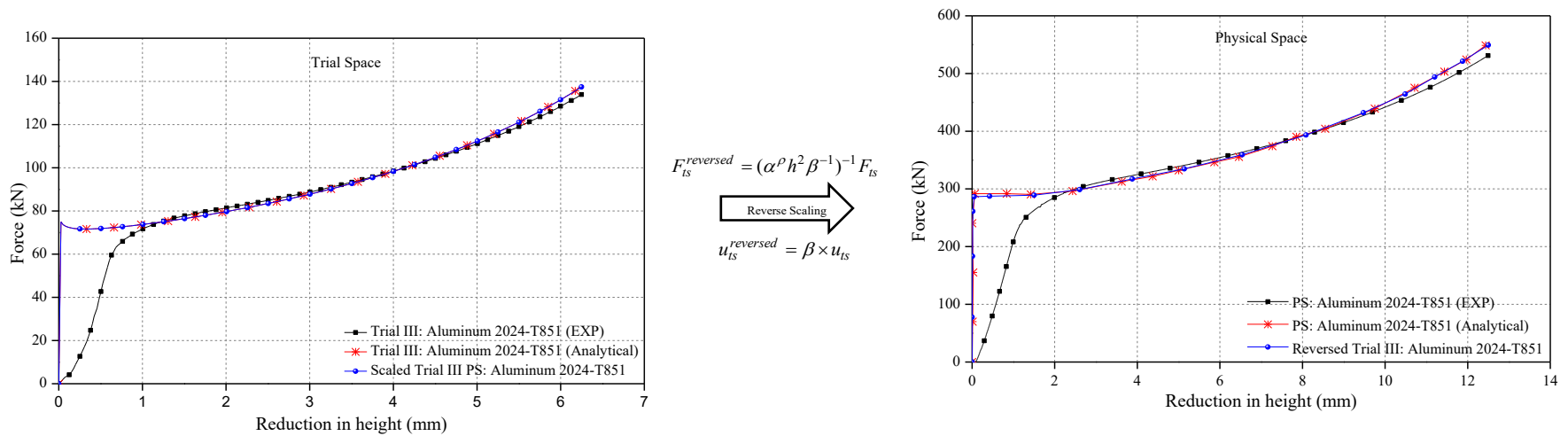

(c)

Fig. 14. Experimental and analytical results of force-reduction in height in physical and trial spaces for cylinders. 

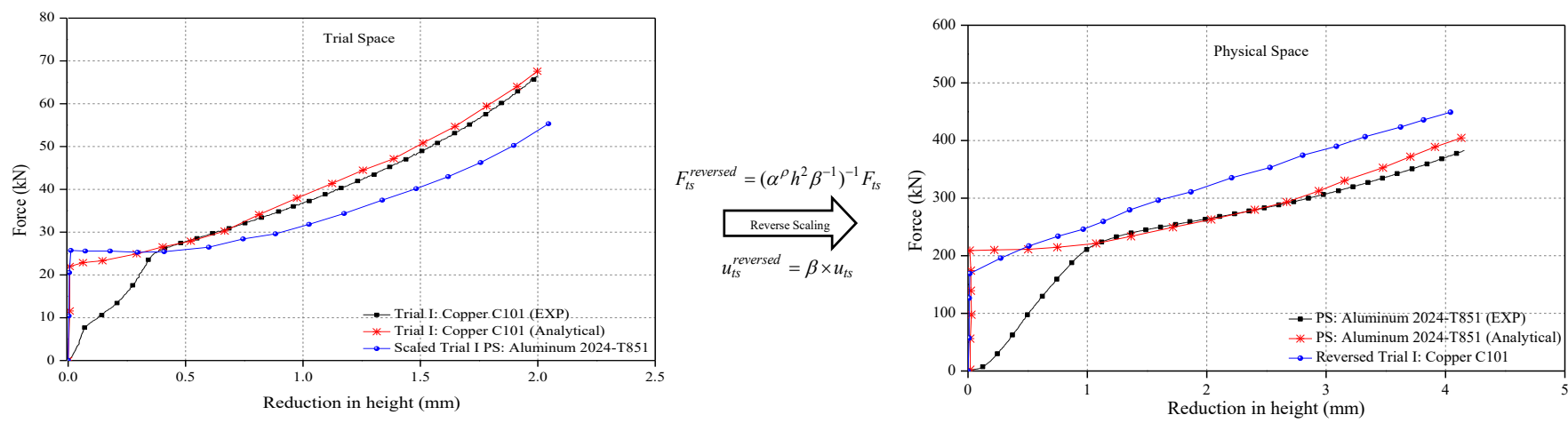

(a)
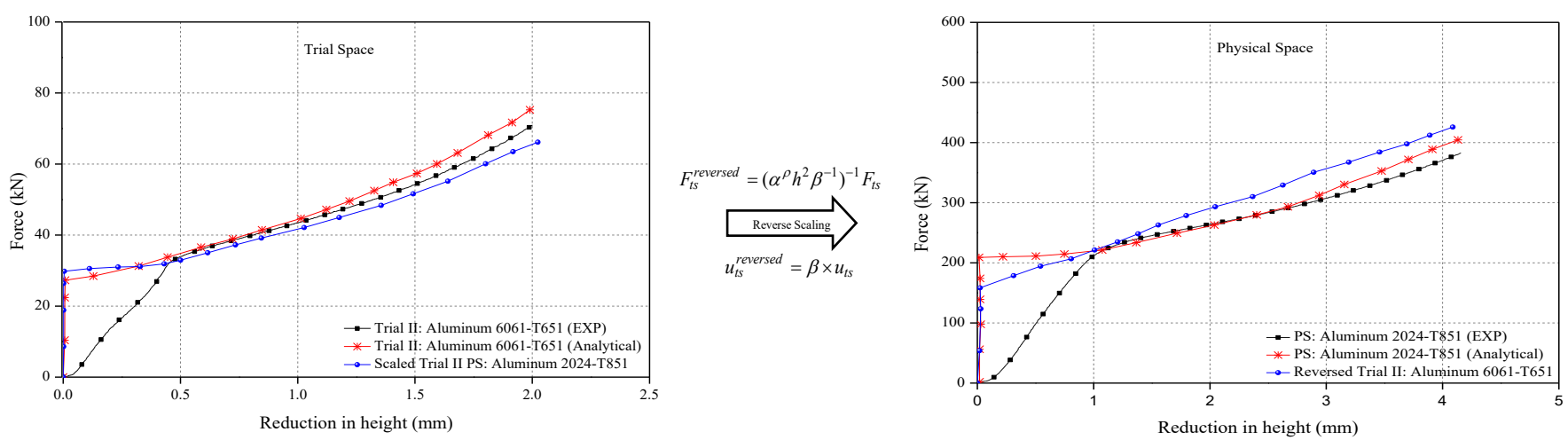

(b)
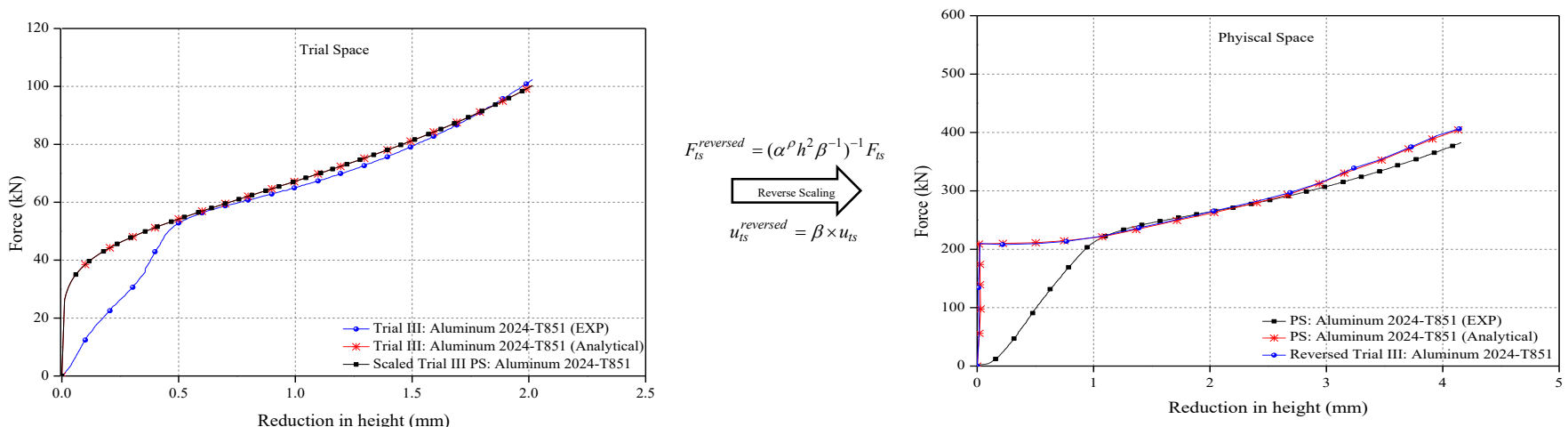

(c)

Fig.15. Experimental and analytical results of force-reduction in height in physical and trial spaces for rings. 


\section{Conclusions}

In this paper, the finite similitude concept is presented, discussed and validated experimentally, numerically and analytically for the cold upsetting tests. This scaling methodology is founded on proportional transfers between two regions of space (scaled and unscaled) using transport equations for volume, mass, momentum, movement, energy and entropy. The investigation in this paper revealed:

- The scaling theory has been shown to be applicable to the cold upsetting process for cylindrical and ring shaped billets despite the absence of exact finite similitude.

- Experimental, numerical and analytical models have all been scaled using the finitesimilitude theory which is applicable to all continuum mechanics and involves the application of universally applicable scaling identities.

- Best results were obtained in this study with the use of an identical material in the trial and physical space, which is a direct consequence of the existence of exact finite similitude in the special case of cold upsetting with similitude boundary conditions.

- The investigation revealed that inexact finite similitude permits the use of dissimilar materials in the physical and trial spaces but limited to accuracies of the order of 5 to $10 \%$ depending on material similarity and boundary conditions.

\section{Acknowledgements}

The authors would like to acknowledge the Higher Committee for Education Development in Iraq and the Department of Electromechanical Engineering at Technology University for providing support for Anees Al-Tamimi to facilitate his doctoral research at the University of Manchester. In addition, acknowledgement and thanks are made to the EPSRC for financial support in the form of an EPSRC HVM Catapult Fellowship to enable Dr Davey to work on the scaling theory at the Advanced Forming Research Centre (AFRC) in Glasgow UK.

\section{References}

ALTAN, T., HENNING, H. \& SABROFF, A. 1968. The Use of Model Materials in Predicting Forming Loads in Metalworking. BATTELLE MEMORIAL INST COLUMBUS OH COLUMBUS LABS.

ALTAN, T. \& LEE, C. 1972. Influence of flow stress and friction upon metal flow in upset forging of rings and cylinders. Journal of Engineering for Industry. Transactions of the ASME, 94, 775-782.

CHANG, K. \& BRITTAIN, T. 1968. An investigation of analog materials for the study of deformations in metal processing simulations. Journal of Engineering for Industry, 90, 381-386.

CHO, U., DUTSON, A. J., WOOD, K. L. \& CRAWFORD, R. H. 2005. An advanced method to correlate scale models with distorted configurations. Journal of Mechanical Design, 127, 78-85. 
DARVIZEH, R. \& DAVEY, K. 2012. Strategies for incorporating material discontinuities into finite element formulations. Computational Methods For Engineering Science, 167-192.

DAVEY, K. \& DARVIZEH, R. 2016. Neglected transport equations: extended RankineHugoniot conditions and J-integrals for fracture. Continuum Mechanics and Thermodynamics, 1-28.

DAVEY, K., DARVIZEH, R. \& AL-TAMIMI, A. 2017. Scaled metal forming experiments: a transport equation approach. International Journal of Solids and Structures, 125, 184-205.

DIETER, G. E., KUHN, H. A. \& SEMIATIN, S. L. 2003. Handbook of workability and process design, ASM international.

DIETER JR, G. E. 1976. Mechanical Metallurgy, Metallurgy and Metallurgical Engineering Series. McGraw-Hill, New York.

HE, A., XIE, G., ZHANG, H. \& WANG, X. 2013. A comparative study on Johnson-Cook, modified Johnson-Cook and Arrhenius-type constitutive models to predict the high temperature flow stress in 20CrMo alloy steel. Materials \& Design, 52, 677-685.

HERTEL, H. 1966. "Modelltechnische Untersuchung der Fliessvorginge beim Strang-und Gesenkpressen" (Simulated Investigation of Material Flow in Extrusion and Forging),. Automobil-Industrie,, 11, 3-12.

HEUER, P. J. 1962. "Modellverfahren fur die Umformtechnik, Fliessvorg nge, Werkstoffkonstante, Umformbeiwert" (Modeling Methods for Forming Technology,Flow, Material Constant, Forming Factor). VDI Forschungsheft, 493

HIBBITT, H., KARLSSON, B. \& SORENSEN, P. 2011. Abaqus analysis user's manual version 6.10. Dassault Systèmes Simulia Corp.: Providence, RI, USA.

HOSFORD, W. F. \& CADDELL, R. M. 2011. Metal forming: mechanics and metallurgy, Cambridge University Press.

ITSKOV, M. 2007. Tensor algebra and tensor analysis for engineers, Springer.

LUBLINER, J. Plasticity theory. 1990. Teräsosakerroin $\delta a$, kaava, 2, 1,123-0.

MALE, A. T. 1964. A method for the determination of the coefficient of friction of metals under conditions of bulk plastic deformation. J. Inst. Metal., 93, 38-46.

MAZZARIOL, L., OSHIRO, R. \& ALVES, M. 2016. A method to represent impacted structures using scaled models made of different materials. International Journal of Impact Engineering, 90, 81-94.

NAVARRETE, J., NOGUEZ, M., RAMíREZ, J., SALAS, G. \& ROBERT, T. 2001. Die forging stress determination: a dimensional analysis approach. Journal of manufacturing science and engineering, 123, 416-419.

OSHIRO, R. \& ALVES, M. 2009. Scaling of structures subject to impact loads when using a power law constitutive equation. International Journal of Solids and Structures, 46, 3412-3421.

PAWELSKI, O. 1964. Beitrag zur Ahnlichkeitstheorie der Umformtechnik (Contribution to Theory of Similitude in Forming Technology). Archiv f. Eisenhiuttenwesen, 35, 1-10.

PAWELSKI, O. 1992. Ways and limits of the theory of similarity in application to problems of physics and metal forming. Journal of Materials Processing Technology, 34, 1930 .

SEDOV, L. I. 1993. Similarity and dimensional methods in mechanics, CRC press.

SOFUOGLU, H. \& RASTY, J. 1999. On the measurement of friction coefficient utilizing the ring compression test. Tribology International, 32, 327-335. 
STANDARD, A. 1990. Standard test methods of compression testing of metallic materials at room temperature. 1990 Annual Book of ASTM Standards, ASTM, West Conshohocken, PA, 98-105.

VANSANT, O. 1967. Mathematical analysis for axial compression of a flat ring. INST MATERIALS 1 CARLTON HOUSE TERRACE, LONDON SW1Y 5DB, ENGLAND.

WESTINE, P. S. \& MULLIN, S. A. 1987. Scale modeling of hypervelocity impact. International Journal of Impact Engineering, 5, 693-701. 